\title{
The exchange of SVOCs across the air-sea interface in Singapore's coastal environment
}

\author{
J. He ${ }^{1,2}$ and R. Balasubramanian ${ }^{2,1}$ \\ ${ }^{1}$ Singapore - Delft Water Alliance, Block E1, \#08-25, 1 Engineering Drive 2, National University of Singapore, \\ 117576 Singapore \\ ${ }^{2}$ Division of Environmental Science and Engineering, Block E1A, \#02-19, 1 Engineering Drive 2, National University of \\ Singapore, 117576 Singapore
}

Received: 17 May 2009 - Published in Atmos. Chem. Phys. Discuss.: 16 June 2009

Revised: 27 November 2009 - Accepted: 10 February 2010 - Published: 17 February 2010

\begin{abstract}
Coastal areas are vulnerable to the accumulation of semivolatile organic compounds, such as PAHs, OCPs and PCBs from atmospheric inputs. Dry particulate and wet depositions, and air-water diffusive exchange in the Singapore's south coastal area, where most of chemical and oil refinery industries are situated in, were estimated. Based on a yearly dataset, the mean annual dry particulate deposition fluxes of $\sum_{16}$-PAHs, $\sum_{7}$ OCPs and $\sum_{21}$ PCBs were $1328.8 \pm 961.1 \mu \mathrm{g} \mathrm{m}^{-2} \mathrm{y}^{-1}$, $5421.4 \pm 3426.7 \mathrm{ng} \mathrm{m}^{-2} \mathrm{y}^{-1}$ and $811.8 \pm 578.3 \mathrm{ng} \mathrm{m}^{-2} \mathrm{y}^{-1}$, and the wet deposition of $\sum_{16}$-PAHs and $\sum_{7}$ OCPs were $6667.1 \pm 1745.2$ and $115.4 \pm 98.3 \mu \mathrm{g} \mathrm{m}^{-2} \mathrm{y}^{-1}$, respectively. Seasonal variation of atmospheric depositions was influenced by meteorological conditions. Air-water gas exchange fluxes were shown to be negative values for PAHs, $\mathrm{HCHs}$ and DDXs, indicating Singapore's south coast as a sink for the above-mentioned SVOCs. The relative contribution of each depositional process to the total atmospheric input was assessed by annual fluxes. The profile of dry particulate deposition, wet deposition and gas exchange fluxes seemed to be correlated with individual pollutant's properties such as molecular weight and Henry's law constant, etc. For the water column partitioning, the organic carbon-normalized partition coefficients between particulate and dissolved phases $\left(K_{\mathrm{OC}}\right)$ for both PAHs and OCPs were obtained. The relationships between $K_{\mathrm{OC}}$ of PAHs and OCPs and their respective octanol-water partition coefficient $\left(K_{\mathrm{OW}}\right)$ were examined. In addition, both adsorption onto combustion-derived soot car-
\end{abstract}

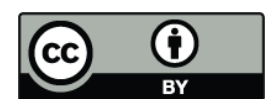

Correspondence to: R. Balasubramanian (eserbala@nus.edu.sg) bon and absorption into natural organic matter for PAHs in marine water column were investigated. Enrichment factors in the sea-surface microlayer (SML) of the particulate phase were 1.2-7.1 and 3.0-4.9 for PAHs and OCPs, and those of dissolved phase were 1.1-4.9 and 1.6-4.2 for PAHs and OCPs, respectively. These enrichment factors are relatively higher than those reported for nearby coastal areas, which are most likely due to more organic surfactants floating in the south coastal surface of Singapore.

\section{Introduction}

Semi-volatile organic compounds (SVOCs) such as polycyclic aromatic hydrocarbons (PAHs), organo-chlorine pesticides (OCPs) and polychlorinated biphenyls (PCBs) can be transported widely from their original sources. These three groups of pollutants, PAHs, OCPs and PCBs, have been studied for decades due to their inherent toxicity, persistence and ability to disperse in the environment (Iwata et al., 1993; Jones and De Voogt, 1999; Oskam et al., 2004). These compounds can be introduced into the environment via the atmosphere, for example, in the emissions of incomplete combustion of fossil fuels (e.g. PAHs), out-gassing from pollutantcontaining media such as paints, transformers and capacitors etc. (e.g. PCBs) and by spraying onto soils and vegetation (e.g. OCPs). Major urban and industrial centers increase loadings of SVOCs to proximate sea waters through riverine transport, atmospheric deposition via dry particle deposition, wet deposition, and air-sea gas exchange (McVeety and Hites, 1988; Bidleman et al., 1995; Park et al., 2002; Fang et al., 2008). In addition to acting as sinks for SVOCs,

Published by Copernicus Publications on behalf of the European Geosciences Union. 
oceans can act as sources of SVOCs to coastal atmospheres and play important roles in the global biogeochemistry of SVOCs (Hinckley et al., 1991; Dachs et al., 1999, 2002). Particle-sorbed SVOCs can settle to the ocean surface by dry particle deposition, a uni-directional advective transport process from the atmosphere to the water, the removal rate by which is a function of the physical and chemical properties of the aerosols and bound pollutants, meteorological conditions and surface characteristics (Wania et al., 1998; Odabasi et al., 1999). In addition, SVOCs are removed from the atmosphere and transported to the waters by precipitation scavenging of atmospheric vapors and particles, which are incorporated into the rain within or below the clouds. After SVOCs are deposited into the bulk seawater, water-column partitioning can affect the distribution of pollutants between the dissolved aqueous and the solid phases and eventually impact the fate of these compounds in oceans (Luo et al., 2004). Other than the abovementioned processes, air-sea exchange can make SVOCs diffuse across the air-sea interface; however, the sea surface microlayer (SML), a unique compartment at the airsea boundary defined operationally as the upper millimeter $(1-1000 \mu \mathrm{m})$ of the sea surface, has large storage capacity to delay the transport of SVOCs across the interface. This interfacial effect has been reported as the enrichment of contaminants with different physicochemical properties (Hardy, 1982; Chernyak et al., 1996; Wurl et al., 2006a).

Although a considerable number of studies as mentioned above have been conducted to assess the SVOCs exchange between air-sea interface across wide geographical areas, little work has been done to determine the significance of these fate and transfer processes of SVOCs in Southeast Asia. The tropical regions of Asia are considered to be an important source of many SVOCs (Iwata et al., 1994). Those SVOCs with a $\log K_{\mathrm{OA}}$ of around 8 and a $\log K_{\mathrm{OW}}$ of around -2 such as PCBs and OCPs can be classified as "multi-hoppers", which can volatilize effectively after deposition to either soils and waters and thus undergo "multiple hops" to migrate from tropical to temperate and even polar regions (Wania, 2003). In Southeast Asia, Basheer et al. (2003) have characterized persistent organic pollutants (PAHs, OCPs and PCBs) in Singapore's northeastern and southwestern coastlines surface seawater, but have not investigated any air-sea exchange processes mentioned above. Wurl et al. (2006) have studied the distribution of organochlorine compounds (OCs, including OCPs and PCBs) in the SML and subsurface water (SSW) in Hong Kong. Wurl and Obbard (2006b) have also determined the occurrence of OCs in the water column of shallow Johor Strait, between Malaysia and northeastern Singapore, by short-term measurements; in addition, Wurl et al. (2006a) have investigated the role of the SML in airsea gas exchange of OCs by snapshot sampling in the same sites of Johor Straits. However, the latter work by Wurl et al. (2006a) was just focused on diffusive exchange, one of the air-sea exchange processes only.
In this study, dry particle deposition and wet deposition of selected SVOCs were investigated based on an extensive set of yearly data. In addition to receiving riverine inflows and direct emissions, coastal areas tend to experience higher atmospheric deposition than the rest of the oceans due to the proximity to the sources which are predominantly land-based. Singapore, a representative country of Southeast Asia, is a small but highly developed island with dense industrial parks in the Southwestern part, where the terrestrial sources affect the surrounding coasts. In this study, Singapore's Southern coastline was chosen during the Northeast monsoon season to evaluate if this coastal area is a sink or source for selected SVOCs via air-sea diffusive exchange as well as to investigate the SML enrichment effect. Furthermore, the water-column partitioning was assessed by a shortterm measurement on different aquatic particulate matrices in the ocean.

\section{Theoretical approach}

Atmospheric sampling was conducted in this study for each event in a consistent manner $\left(24 \mathrm{~h}\right.$ at $\left.250 \mathrm{~L} \mathrm{~min}^{-1}\right)$; weekly concentrations of SVOCs in the atmosphere were computed as arithmetic mean values. In the case of rainwater, the rainfall amount for each event varied. Hence, those concentrations were calculated as volume-weighted mean (VWM) values.

Dry particulate and wet deposition flux can be calculated according to

$$
\begin{aligned}
& F_{\mathrm{dry}}\left(\mu \mathrm{g} \mathrm{m}^{-2} \mathrm{yr}^{-1}\right)=\sum_{i=1}^{12}\left(C_{\mathrm{A}}^{i} \times V_{\mathrm{d}} \times 2592\right) \\
& F_{\mathrm{wet}}\left(\mu \mathrm{g} \mathrm{m}^{-2} \mathrm{yr}^{-1}\right)=\sum_{i=1}^{12}\left(C_{\mathrm{VWM}}^{i} \times P_{\mathrm{W}}^{i} \times 10^{-3}\right)
\end{aligned}
$$

where $C_{A}^{i}, C_{\mathrm{VWM}}^{i}$ are the monthly particulate concentration of pollutant in air $\left(\mathrm{ng} \mathrm{m}^{-3}\right)$ and monthly total (dissolved plus particulate) concentration of pollutant in rain $\left(\mathrm{ng} \mathrm{L}^{-1}\right)$, respectively; $V_{\mathrm{d}}$ is the deposition velocity $\left(\mathrm{ms}^{-1}\right)$ and $P_{\mathrm{W}}^{i}$ is the rainfall $(\mathrm{mm})$ for sampling month $(i) . V_{\mathrm{d}}$ at a particular vertical height is calculated as the inverse of the sum of a number of resistances (Seinfeld and Pandis, 2006) using the following equation.

$$
V_{\mathrm{d}}=\frac{1}{R_{\mathrm{a}}+R_{\mathrm{b}}+R_{\mathrm{a}} R_{\mathrm{b}} v_{\mathrm{s}}}+v_{\mathrm{s}}
$$

where $v_{\mathrm{s}}$ is the gravitational settling velocity (a function of particle size, density, and viscosity), $R_{\mathrm{a}}$ is aerodynamic resistance refers to turbulent transport from the free atmosphere down to the receptor surface $\left(R_{\mathrm{a}}=9 /\left[u \sigma_{\theta}^{2}\right]\right.$, which is a function of wind speed, $u$ and standard deviation of wind speed, $\sigma_{\theta}$ (Turner, 1986) and $R_{\mathrm{b}}$ is quasi laminar layer resistance, 
which is a function of particle size, Brownian diffusion, interception and impaction; $R_{\mathrm{b}}$ on water surface is given by van den Berg et al. (2000). Each of $R_{\mathrm{a}}$ and $R_{\mathrm{b}}$ is site specific and determined to a large extent by atmospheric properties. Meteorological parameters such as ambient temperature (K) of 299.6-303.2, wind speed $\left(\mathrm{m} \mathrm{s}^{-1}\right)$ of 1.1-3.6, and standard deviation of wind direction $\sigma_{\theta}$ (rad) of 0.13-0.78 were observed during the sampling period. In Southeast Asia (SEA) air, a majority of aerosols observed in the size range of 0.1$20 \mu \mathrm{m}$ by an optical particle counter was in the fine mode (less than $1 \mu \mathrm{m}$ ) (Kondo et al., 2004).

SVOCs in the water column partition into three phases: the truly dissolved phase, the particulate phase and the colloidal organic material (Totten et al., 2001). The truly dissolved and colloidal phases can be categorized as apparent dissolved phase, which refers to the non-filter retained fraction. The partitioning of SVOCs onto particulate and colloidal phases results in the removal of SVOCs from surface layers via gravitational settling and consequently reduces their volatilization rates (Wania et al., 1998). Based on the empirical estimation of sorption of hydrophobic pollutants onto natural sediments and soils (Karickhoff, 1981) and its application into water-column by Totten et al. (2001), the relationship between partition coefficient $K_{\mathrm{OC}}$ and $K_{\mathrm{OW}}$ can be derived as follows:

$\log K_{\mathrm{OC}}=\log \left(\frac{K_{\mathrm{P}}}{f_{\mathrm{OC}}}\right)=a \log K_{\mathrm{OW}}+b$

where $K_{\mathrm{OC}}$ equals partition coefficient $K_{\mathrm{P}}$ normalized by organic carbon fraction $\left(f_{\mathrm{OC}}\right)$ in particulate phase. $K_{\mathrm{P}}$ refers to the partitioning in the water column between the apparent dissolved and particulate phase (Totten et al., 2001), calculated as $C_{\mathrm{P}} /\left(C_{\mathrm{d}, \mathrm{a}} \times \mathrm{TSM}\right)\left(C_{\mathrm{P}}\right.$ : the concentration of SVOCs associated with the particulate phase; $C_{\mathrm{d}, \mathrm{a}}$ : the concentration in the apparent dissolved phase; and TSM: the concentration of total suspended matter). $K_{\mathrm{OW}}\left(\mathrm{L} \mathrm{kg}^{-1}\right)$ was obtained from the best available experimental data and predictive models with careful evaluations (de Lima Ribeiro and Ferreira, 2003; Xiao et al., 2004; Shen and Wania, 2005; Zhou and Zhu, 2005; Lü et al., 2007). Since the temperature dependence of $K_{\text {Ow }}$ for selected SVOCs is not significant (Bahadur et al., 1997; Lei et al., 2000) and the temperature of the seawater varied by no more than $4{ }^{\circ} \mathrm{C}$ in this study, $K_{\text {Ow }}$ has not been corrected for temperature.

To accommodate additional sorption to soot phase, Accardi-dey and Gschwend (Accardi-dey and Gschwend, 2002) modified Gustafsson's model (Gustafsson et al., 1997) to yield a dual OC/BC model:

$K_{\mathrm{P}}=f_{\mathrm{OC}} K_{\mathrm{OC}}+f_{\mathrm{SC}} K_{\mathrm{SC}} C_{\mathrm{d}, \mathrm{a}}^{n-1}$

where $f_{\mathrm{SC}}, K_{\mathrm{SC}}$ are soot carbon fraction in particulate phase of seawater and soot-water partition coefficient, respectively, and $n$ is Freundlich constant. If $n=1$, this model assumes that soot-water partition was a linear isotherm, otherwise it is a nonlinear process. This model has been applied to multi media and especially the sediment-water (porewater) partitioning (Gustafsson et al., 1997; Cornelissen and Gustafsson, 2005; Prevedouros et al., 2008). Considering the similarity of distribution between sediment/water and between particulate/water in sea water column, Eq. (5) can be reasonably applied to the latter process.

The apparent dissolved concentrations of SVOCs $\left(C_{\mathrm{d}, \mathrm{a}}\right)$ is the sum of the truly dissolved $\left(C_{\text {truly }}\right)$ and colloidal $\left(C_{\mathrm{DOC}}\right.$, DOC-dissolved organic carbon, $\mathrm{mg} \mathrm{L}^{-1}$ ) phases, onto both of which the fractions of SVOCs partitioned can be estimated as described in Eq. (5) by Totten et al. (2001) and Wurl et al. (2006a)

$C_{\mathrm{d}, \mathrm{a}}=C_{\text {truly }}+C_{\mathrm{DOC}}=C_{\text {truly }}\left(1+K_{\mathrm{OW}} \times \mathrm{DOC} \times 10^{-7}\right)$

A classical two-layer model, which has been previously applied to the air-sea exchange of SVOCs (Achman et al., 1993; Zhang et al., 2007; Li et al., 2009), assumes that the rate of gas transfer is controlled by the pollutant's ability to diffuse across the air layer and sea surface water on either side of the air-water interface. The molecular diffusivity of the pollutant, dependent on the amount of resistance encountered in the liquid and gas films, describes the rate of transfer while the concentration gradient drives the direction of transfer (Totten et al., 2001). The flux $F\left(\mathrm{ng} \mathrm{m}^{-2} \mathrm{day}^{-1}\right)$ is calculated by

$F=K_{\mathrm{OL}}\left(C_{\text {truly }}-\frac{C_{\mathrm{a}}}{H^{\prime}}\right)$

where $K_{\mathrm{OL}}\left(\mathrm{m} \mathrm{day}^{-1}\right)$ is the overall mass transfer coefficient, and $\left(C_{\text {truly }}-\frac{C_{\mathrm{a}}}{H^{\prime}}\right)$ describes the concentration gradient $\left(\mathrm{ng} \mathrm{m}^{-3}\right)$ where $C_{\mathrm{a}}$ is the gas-phase concentration of the compound in air that is divided by the dimensionless Henry's law constant $(H)$ with $H=H / R T$ where $R$ is the universal gas constant $\left(8.315 \mathrm{~Pa} \mathrm{~m}^{3} \mathrm{~K}^{-1} \mathrm{~mol}^{-1}\right), H$ is Henry's law constant $\left(\mathrm{Pa} \mathrm{m}^{3} \mathrm{~mol}^{-1}\right)$ corrected by the temperature and salinity, and $T$ is the temperature at the air-water interface (K). A positive flux indicates net volatilization out of the seawater and a negative flux indicates net absorption into the seawater. The overall mass transfer coefficient $\left(K_{\mathrm{OL}}\right)$ comprises resistances to mass transfer across the air layer and the water layer.

$\frac{1}{K_{\mathrm{OL}}}=\frac{1}{K_{\mathrm{W}}}+\frac{1}{K_{\mathrm{a}} H^{\prime}}$

where $K_{\mathrm{a}}$ and $K_{\mathrm{W}}\left(\mathrm{m} \mathrm{day}^{-1}\right)$ are the mass transfer coefficients across the air layer and water layer, respectively. The mass transfer coefficient $K_{\mathrm{a} \text {,comp }}\left(\mathrm{cm} \mathrm{s}^{-1}\right)$ for a compound in air was calculated using the following equation (Schwarzenbach et al., 2003):

$K_{\mathrm{a}, \text { comp }}=K_{\mathrm{a}, \mathrm{H}_{2} \mathrm{O}}\left(\frac{M_{\mathrm{H}_{2} \mathrm{O}}}{M_{\text {comp }}}\right)^{-0.5 \times 0.67}$

where $K_{\mathrm{a}, \mathrm{H}_{2} \mathrm{O}}=0.2 \times u_{10}+0.3$ and $M\left(\mathrm{~g} \mathrm{~mol}^{-1}\right)$ is molar mass of the compound. Wanninkhoff's quadratic equation 
(Wanninkhof, 1992) for the mass transfer coefficient $K_{\mathrm{w}}$ has been applied in a number of studies (Totten et al., 2001; Wanninkhof et al., 2004; Wurl et al., 2006a), but this relationship was a semi-empirical estimation with low correlation $\left(r^{2}=0.66\right)$ only at steady winds. A more robust model was thus used in this study to calculate $K_{\mathrm{w}, \mathrm{comp}}\left(\mathrm{cm} \mathrm{s}^{-1}\right)$ for compounds of interest (Schwarzenbach et al., 2003):

$$
\begin{aligned}
& K_{\mathrm{w}, \text { comp }}= \\
& \left\{\begin{array}{l}
0.65 \times 10^{-3}\left(\frac{S c_{\text {comp }}}{600}\right)^{-0.67} \text { for } u_{10} \leq 4.2 \mathrm{~ms}^{-1}(\text { smooth surface regime) } \\
\left(0.79 u_{10}-2.68\right) \times 10^{-3}\left(\frac{S c_{\text {comp }}}{600}\right)^{-0.5} \text { for } 4.2<u_{10} \leq 13 \mathrm{~ms}^{-1} \text { (rough surface regime) } \\
\left(1.64 u_{10}-13.69\right) \times 10^{-3}\left(\frac{8 c_{\text {comp }}}{600}\right)^{-0.5} \text { for } u_{10}>13 \mathrm{~ms}^{-1} \text { (breaking wave regime) }
\end{array}\right.
\end{aligned}
$$

where the Schmidt number, $S c$, is the ratio of kinematic viscosity $v_{\text {kin }}\left(\mathrm{cm}^{2} \mathrm{~s}^{-1}\right)$ and diffusivity $D\left(\mathrm{~cm}^{2} \mathrm{~s}^{-1}\right)$ by $S c=v_{\text {kin }} / D$. The kinematic viscosity of seawater is obtained using the method recommended by Chen et al. (1973). The diffusivities of compounds of interest in seawater were calculated using the Eq. (1) developed by Wilke and Chang (1955).

$D=7.4 \times 10^{-8} \frac{\left(2.6 M_{\text {comp }}\right)^{0.5} T}{\eta V_{\text {comp }}^{0.6}}$

where $T$ is the average temperature during each sampling event, $V_{\text {comp }}$ is the molar volume of compound investigated (Mackay et al., 1992, 1996) and $\eta$ is equal to the kinematic viscosity of solution (here referring to seawater). The important parameters involved in the abovementioned equations are listed in Table 1.

However, the abovementioned relationships between $K_{\mathrm{w}, \text { comp }}$ and $u_{10}$ are only applicable to the clean water surface. A number of studies showed that the presence of surfactants in SML drastically reduces the rate of gas transport across the water surface (Asher and Pankow, 1986; Frew et al., 1990; Tsai and Liu, 2003). Adopting the experimental data of Broecker et al. (1978) and the finding of Jähne et al. (1987) that the presence of surfactants could increase the $S c$ exponent, Asher (1997) proposed a linear $K_{\mathrm{w}, \text { comp }}$ $\left(\mathrm{cm} \mathrm{s}^{-1}\right)-u_{10}$ relationship for the sea surface with surfactant coverage:

$K_{\mathrm{w}, \text { comp }}=2.78 \times 10^{-4}\left(1.04 u_{10}-0.12\right)\left(\frac{S c_{\text {comp }}}{600}\right)^{-0.67}$

It is know that for sparingly soluble nonreactive gases such as SVOCs, the liquid-phase interfacial boundary layer resistance is much greater than the gas-phase interfacial boundary layer resistance and the transfer is liquid-phase rate controlled with $K_{\mathrm{OL}}$ approximately equal to $K_{\mathrm{w}, \mathrm{comp}}$ (Asher, 1997).

\section{Experimental}

\subsection{Sampling}

Dry and Wet Deposition Sampling. For the study of depositional fluxes of selected SVOCs, both the atmospheric and precipitation samples were collected simultaneously at the National University of Singapore (NUS) atmospheric research station. Altogether, 37 atmospheric particulate samples and 32 rainwater samples were collected under different weather conditions between June 2007 and May 2008. The sampling site was located $67 \mathrm{~m}$ above sea level and was approximately $1 \mathrm{~km}$ away from the open sea.

Particulate and gaseous SVOCs in the atmosphere were collected separately using a high volume sampler (Model: TE-1000PUF, Tisch Environmental, Inc. USA) by drawing air through pre-combusted $10 \mathrm{~cm}$ circular quartz microfiber filters (backup filters applied, Whatman, Tisch Environmental, Inc. USA) and polyurethane foam plugs (PUF, TE-1012, Tisch Environmental, Inc. USA) in series at ca. $250 \mathrm{~L} \mathrm{~min}^{-1}$ on an event basis for 24-48 h every week, namely, three to four samples were collected every month. The rainwater samples were collected by an automated wet-only sampler (Model US-330, Ogasawara Keiki Seisakusho, Tokyo, Japan). All rainwater samples were stored in an internal refrigerator at $4{ }^{\circ} \mathrm{C}$ by the automated sampler immediately during a rain event and collected back to the lab within $24 \mathrm{~h}$ after each rain event. After collection, rainwater samples were filtered with pre-cleaned (heated at $450^{\circ} \mathrm{C}$ for $24 \mathrm{~h}$ ) Whatman GF/F filters $(0.7 \mu \mathrm{m}, 47 \mathrm{~mm}$ i.d. $)$. The actual volume of each sample collected was measured and recorded after filtration. Before and after filtration, GF/F filters were conditioned in a dry box (maintained at $22^{\circ} \mathrm{C}$ and $30 \% \mathrm{RH}$ ), and then weighed to calculate the mass of suspended particles.

SSW and SML Sampling. The SSW samples were collected at the depth of $1 \mathrm{~m}$ at a southern coastal area of Singapore with a $2 \mathrm{~L}$ glass amber bottle inserted in a stainlesssteel sampling device. The SML samples (approximately $1 \mathrm{~L})$ were collected simultaneously using the glass plate technique (Harvey and Burzell, 1972) and stored in an amber glass container. Eight samples were collected for SSW and SML, respectively. After collection, the same filtration process, as used with rainwater samples, was applied.

Air Sampling. Atmospheric samples were collected simultaneously with SSW by a high volume sampler (Model: TE1000PUF, Tisch Environmental, Inc. USA) with quartz microfiber filters (Whatman, Tisch Environmental, Inc. USA) to capture particles and polyurethane foam plugs (PUF, TE1012, Tisch Environmental, Inc. USA) in series $(7.62 \mathrm{~cm})$ at ca. $250 \mathrm{~L} \mathrm{~min}^{-1}$ to collect gaseous phase. Particles were collected by a pre-combusted (at $450^{\circ} \mathrm{C}$ for $24 \mathrm{~h}$ ) circular quartz filter of 4 inches diameter, followed by a combination of 3 PUF plugs connected in series $(7.62 \mathrm{~cm})$ to trap gas phase compounds. Eight paired samples (SSW+atmospheric gas) were collected.

Meteorological Conditions. The relevant meteorological parameters (air temperature, rainfall, wind speed, etc.) were obtained from an automated NUS weather station located in the same building where the atmospheric station is located. This meteorological station has been in operation to provide real-time meteorological data to the NUS community. 
Table 1. 1. Relevant parameters used in this study (source indicated in the text).

\begin{tabular}{lcccccc}
\hline Compound & $\log K_{\mathrm{OW}}$ & $H\left(\times 10^{-4}\right)$ & $K_{\mathrm{a}, \mathrm{comp}}\left(\mathrm{cm} \mathrm{s}^{-1}\right)$ & $D\left(\times 10^{-5} \mathrm{~cm}^{2} \mathrm{~s}^{-1}\right)$ & $S c_{\mathrm{comp}}\left(\times 10^{-4}\right)$ & $V_{\mathrm{comp}}\left(\mathrm{cm}^{3} \mathrm{~mol}^{-1}\right)$ \\
\hline Naph & 3.37 & $1.28-1.48$ & $0.99-1.96$ & $1.95-2.00$ & $4.46-4.72$ & 169.8 \\
Ace & 3.92 & $79.5-88.8$ & $1.06-2.08$ & $2.12-2.17$ & $4.12-4.36$ & 173.0 \\
Flu & 4.18 & $45.4-50.4$ & $1.09-2.13$ & $2.09-2.14$ & $4.17-4.42$ & 188.0 \\
Phe & 4.57 & $19.7-21.7$ & $1.11-2.19$ & $2.09-2.14$ & $4.17-4.41$ & 199.0 \\
Ant & 4.54 & $23.9-26.5$ & $1.11-2.19$ & $2.10-2.16$ & $4.14-4.39$ & 197.0 \\
Flt & 5.22 & $8.17-8.84$ & $1.16-2.28$ & $2.11-2.17$ & $4.12-4.37$ & 217.3 \\
Pyr & 5.18 & $8.12-8.90$ & $1.16-2.28$ & $2.13-2.19$ & $4.09-4.33$ & 214.0 \\
B(a)A & 5.91 & $5.42-6.20$ & $1.21-2.37$ & $2.07-2.13$ & $4.20-4.45$ & 248.0 \\
Chry & 5.86 & $2.58-3.20$ & $1.21-2.37$ & $2.06-2.11$ & $4.23-4.48$ & 251.0 \\
B(b)F & 5.75 & $0.29-0.32$ & $1.25-2.46$ & $2.08-2.13$ & $4.19-4.44$ & 268.9 \\
B(k)F & 6.00 & $0.26-0.29$ & $1.25-2.46$ & $2.08-2.13$ & $4.19-4.44$ & 268.9 \\
B(a)P & 6.04 & $0.20-0.22$ & $1.25-2.46$ & $2.11-2.16$ & $4.14-4.38$ & 263.0 \\
Ind & 6.54 & $0.15-0.16$ & $1.29-2.53$ & $2.14-2.19$ & $4.08-4.32$ & $277.0^{\mathrm{a}}$ \\
B(ghi)P & 6.50 & $0.14-0.15$ & $1.29-2.53$ & $2.14-2.19$ & $4.08-4.32$ & 277.0 \\
$\alpha$-HCH & 3.82 & $1.47-1.61$ & $1.31-2.57$ & $2.37-2.43$ & $3.68-3.90$ & 243.6 \\
$\beta$-HCH & 3.80 & $0.17-0.19$ & $1.31-2.57$ & $2.37-2.43$ & $3.68-3.90$ & 243.6 \\
$\gamma$-HCH & 3.72 & $1.10-1.15$ & $1.31-2.57$ & $2.37-2.43$ & $3.68-3.90$ & 243.6 \\
4,4 '-DDD & 6.33 & $4.80-5.22$ & $1.35-2.66$ & $2.14-2.19$ & $4.08-4.32$ & 312.6 \\
4,4 -DDE & 6.93 & $29.0-33.1$ & $1.35-2.65$ & $2.16-2.22$ & $4.03-4.27$ & 305.2 \\
4,4 '-DDT & 6.39 & $5.05-5.73$ & $1.40-2.75$ & $2.16-2.22$ & $4.03-4.26$ & 333.5 \\
\hline
\end{tabular}

a The molar volume of Ind is not available yet to the best of our knowledge. Due to its similarity of molecular structure and weight to $\mathrm{B}$ (ghi)P, it is reasonably presumed that the molar volume of $\mathrm{B}$ (ghi)P could be used for Ind.

After collection, all water samples were filtered with precleaned (heated at $450{ }^{\circ} \mathrm{C}$ for $24 \mathrm{~h}$ ) Whatman GF/F filters $(0.7 \mu \mathrm{m}, 47 \mathrm{~mm}$ i.d.). The actual volume of each sample collected was measured and recorded after filtration. Before and after filtration, GF/F filters were conditioned in a dry box (maintained at $22^{\circ} \mathrm{C}$ and $30 \% \mathrm{RH}$ ), and then weighed to calculate the mass of suspended particles.

\subsection{Materials}

All solvents used for this study were of pesticide grade: n-hexane (HEX), acetone (ACE), dichloromethane (DCM) and methanol (METH) (Tedia, USA). The standard mixture USEPA 610 including 16 priority PAHs (naphthalene (Naph), acenaphthylene (Acy), acenaphthene (Ace), fluorene (Flu), phenanthrene (Phe), anthracene (Ant), fluoranthene (Flt), pyrene (Pyr), benz[a]anthracene (B(a)A), chrysene (Chry), benzo[b]fluoranthene (B(b)F), benzo[k]fluoranthene $(\mathrm{B}(\mathrm{k}) \mathrm{F})$, benzo[a]pyrene $(\mathrm{B}(\mathrm{a}) \mathrm{P})$, indeno[1,2,3-cd]pyrene (Ind), dibenz[a,h]anthracene $(\mathrm{DB}(\mathrm{ah}) \mathrm{A})$ and benzo[ghi]perylene $(\mathrm{B}(\mathrm{ghi}) \mathrm{P}))$, in methanol: methylene chloride and the standard mixture of OCPs included in Kit 608-S were purchased from Supelco (USA); standard for PCBs (C-QME-01) was obtained from AccuStandard (New Haven, USA). Surrogate standards were used as follows: anthracene- $\mathrm{d}_{10}$, fluoranthene- $\mathrm{d}_{10}$ and benzo[e]pyrene- $\mathrm{d}_{12}$ (Sigma-Aldrich, St. Louis, MO, USA) for PAHs; $13 \mathrm{C}_{12}$-PCB 8 and $13 \mathrm{C}_{6}$-Hexachlorobenzene (Cambridge Isotope Laboratories, MA, USA) for OCPs;
$13 \mathrm{C}_{12}$-PCBs congeners CB 77, 101, 141, 178 (Cambridge Isotope Laboratories, MA, USA) for PCBs. In addition, internal standards were applied as below: phenanthrene- $\mathrm{d}_{10}$, pyrene- $\mathrm{d}_{10}$ and benzo[a]pyrene- $\mathrm{d}_{12}$ (Sigma-Aldrich, St. Louis, MO, USA) for PAHs; $13 \mathrm{C}_{6}$-Tetrachlorobenzene and $13 \mathrm{C}_{12}-4,4$ ' DDT (Cambridge Isotope Laboratories, MA, USA) for OCPs; and $13 \mathrm{C}_{12}$ - PCBs congeners CB 8 and 206 (Cambridge Isotope Laboratories, MA, USA) for PCBs. Silica gel and florisil, obtained from Merck (Germany), were heated at $600^{\circ} \mathrm{C}$ for $24 \mathrm{~h}$ to remove any organic contamination.

\subsection{Sample preparation and analysis}

Sample Extraction and GC-MS Analysis. Prior to extraction, surrogate compounds were added to all samples. Water filters, aerosol filters and PUF samples were extracted separately under optimum conditions (solvent selection, extraction temperature and extraction static time) by Dionex ASE 200. All filtered water samples were extracted on the same day as collection via liquid-liquid extraction using $3 \times 50 \mathrm{~mL}$ DCM aliquots in a two liter separatory funnel (EPA method 3510C). Details of extraction for both air and water samples and purification have been reported somewhere ( $\mathrm{He}$ and Balasubramanian, 2009a, b; He et al., 2009). All extracts were finally blown by gentle nitrogen stream and reduced to $50 \mu \mathrm{L}$ with internal standards, and kept in sealed vials at $-20^{\circ} \mathrm{C}$ prior to GC-MS analysis. 
Chemical analysis was performed using a QP2010 GCMS equipped with a Shimadzu AOC-5000 auto injector and a DB-5 fused silica capillary column $(30 \mathrm{~m}$ length and $0.25 \mathrm{~mm}$ i.d.; film thickness $0.25 \mu \mathrm{m}$ ) with purified helium as carrier gas. $4 \mu \mathrm{L}$ of the sample was injected into the GCMS in splitless mode with a sampling time of $1.5 \mathrm{~min}$ using high-pressure injection mode (pressure 2.47 atm maintained for $2.0 \mathrm{~min}$, initial column flow $3.17 \mathrm{~mL} \mathrm{~min}^{-1}$ ), as recommended in the GC-MS manual (Shimadzu). PAHs, OCPs and PCBs standards as well as extracted samples were measured separately in selective ion monitoring mode (SIM) with a detector voltage $700 \mathrm{~V}$. The most abundant ions were selected for quantification, and then one to four reference ions were used for confirmation of each analyte in SIM mode.

Measurement of OC and EC. Organic carbon (OC) and elemental carbon (EC) were determined by using a laboratory two-step thermal procedure (He and Balasubramanian, 2009c). Carbon contents were obtained by means of the 2400 series II CHNS/O analyzer (Perkin-Elmer Life and Analytical Sciences Inc.), which was operated in CHN mode with acetanilide $(71.09 \% \mathrm{C}, 6.71 \% \mathrm{H}, 10.36 \% \mathrm{H})$ as a calibration standard and with helium plus $8 \%$ oxygen as carrier gas. When the combustion furnace temperature was set at $450^{\circ} \mathrm{C}$, the content of $\mathrm{OC}$ in a sample aliquot put in a combustion boat could be determined directly; when the combustion temperature is set as high as $950^{\circ} \mathrm{C}$, the total of $\mathrm{OC}$ and $\mathrm{EC}$ was determined. Prior to analysis, carbonates are removed by adding diluted $\mathrm{HCl}$. The EC content can then be obtained by subtracting OC from the total of OC and EC. DOC was measured in the filtrate of the SSW using a TOC-5000 Shimadzu instrument by measuring total dissolved carbon and dissolved inorganic carbon to obtain DOC by subtraction.

\subsection{Quality control}

The analytical quality of the data obtained was determined using limit of detection (LOD), recovery, linearity, and by checking sampling artifacts, etc. During each set of extractions, the field blanks (filters and PUFs) were included and the mean blank value was subtracted from the measured levels. Detection limits were derived from the blanks and quantified as the mean plus three times the standard deviation of the concentration in the blanks. LODs for filter and PUF samples ranged from $0.14 \pm 0.16 \mathrm{pg} \mathrm{m}^{-3}$ (4,4'DDE, filter blank) to $0.15 \pm 0.07 \mathrm{ng} \mathrm{m}^{-3}$ (Naph, PUF blank). For the entire water sample analysis, blank tests were performed by using organic-free water, and LODs for water samples ranged from $0.30 \pm 0.17 \mathrm{ng} \mathrm{L}^{-1}$ (Ind) to $1.9 \pm 1.3 \mathrm{ng} \mathrm{L}^{-1}$ (4,4'DDD). The reliability of all extraction procedures was assessed by using surrogate standards for targeted SVOCs. The procedural recoveries of surrogates ranged from $86.7 \pm 6.8 \%$ (anthracene- $\mathrm{d}_{10}$ ) to $97.2 \pm 13.9 \%$ (benzo[e]pyrene-d12). Control calibration standards spiked with internal standards were analyzed regularly to check instrument performance during analysis. The linearity of cali- bration standards was calculated by regression analysis with values ranging from $0.99-1.00\left(r^{2}\right)$ for SVOCs.

A sampling artifact is prone to occur when gaseous SVOCs sorb to filter and particle surfaces, thus leading to an over-estimation of particle-phase SVOCs (Dachs and Eisenreich, 2000). Our sampling strategy here consisted of 24$48 \mathrm{~h}$ sampling. As mentioned above, backup filters were used in this study to correct for gas adsorption of SVOCs to a front filter (Hart and Pankow, 1994). According to the method reported by Mader and Pankow (2001), it was found that less than $5 \%$ of mass recovered from the primary filter was sorbed onto a secondary filter. For the sampling of gaseous SVOCs, breakthrough was evaluated under field conditions by connecting three one-inch plugs in series and analyzing them separately. For $24 \mathrm{~h}$ air samples, measured organic compounds at the third plug were in the range of blank values. Three one-inch plugs used in series with the hi-volume PUF sampler could therefore trap gas-phase target compounds effectively.

\section{Results and discussion}

\subsection{Dry and wet depositions of SVOCs}

By Eqs. (1) and (2), both dry and wet depositions were estimated on an annual basis based on the monthly concentrations of SVOCs as shown in Fig. $1 . V_{\mathrm{d}}\left(0.003 \mathrm{~m} \mathrm{~s}^{-1}\right)$ was not derived from sampling with dry deposition plates in this study but calculated by Eq. (3), which is also in the range of $0.001-0.01 \mathrm{~m} \mathrm{~s}^{-1}$ for PAHs, OCPs and PCBs as reported in the literature (Eisenreich et al., 1981; McVeety and Hites, 1988; Hoff et al., 1996). Concentrations of PCBs in both dissolved and particulate phases of all rainwater samples were below the limits of detection in this study.

In Singapore's coastal area, the monthly dry deposition fluxes for PAHs, OCPs and PCBs were in the range of 46.0-275.6 $\mu \mathrm{g} \mathrm{m}^{-2}$ month $^{-1}$, 60.7-906.1 $\mathrm{ng} \mathrm{m}^{-2}$ month $^{-1}$ and 3.1-93.1 $\mathrm{ng} \mathrm{m}^{-2}$ month $^{-1}$, respectively. A significant increase in the dry deposition fluxes of most investigated pollutants was observed during the pre-NE monsoon (OctoberNovember 2007) as shown in Fig. 1a, especially for PAHs. In this area, periodical monsoon winds could assist in dispersing aerosol particles during NE and SW monsoon seasons; the lighter winds during the pre-monsoon seasons (April-May and October-November) might strengthen the accumulation of particulate SVOCs. The monthly wet deposition flux for PAHs and OCPs ranged from 70.0 $363.5 \mu \mathrm{g} \mathrm{m}^{-2}$ month $^{-1}$ and $4.7-39.9 \mu \mathrm{g} \mathrm{m}^{-2}$ month $^{-1}$, respectively. High wet deposition fluxes were observed from December 2007 to Mar 2008 for both PAHs and OCPs (Fig. 1a in sharp contrast to the low dry deposition fluxes during the same period (Fig. 1b). The rainy season that took place from December 2007 to March 2008 might have contributed to pronounced wet scavenging of aerosols containing 

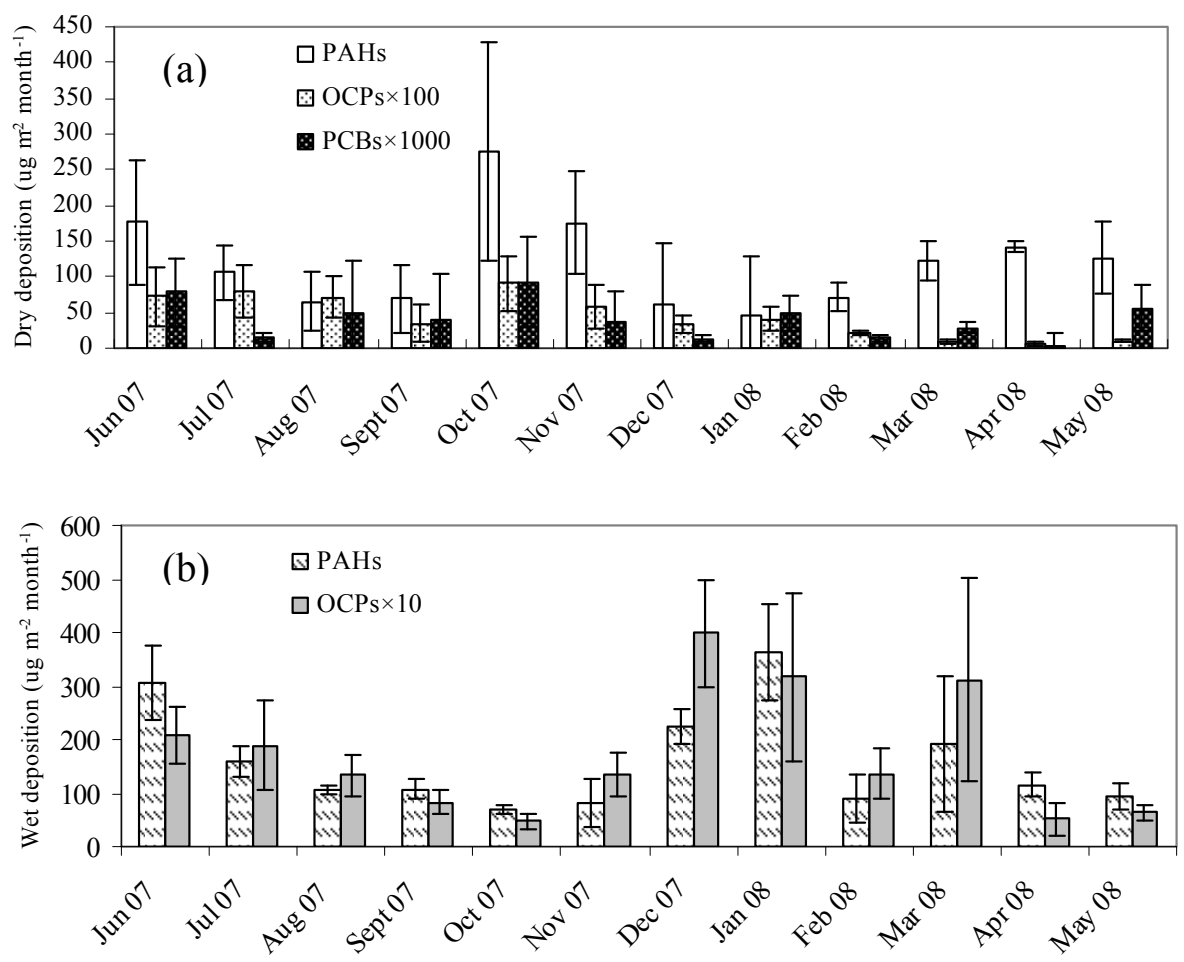

Fig. 1. Seasonal variation in both dry and wet depositions of selected SVOCs between Jun 2007 and May 2008.

SVOCs from the atmosphere. On the other hand, the peak in the dry deposition flux observed during October and November 2007 could likely be due to the typical low wind speeds during pre-monsoon seasons and the relatively less rainfall.

The mean annual atmospheric fluxes of selected SVOCs are summarized in Table 2. Particulate dry deposition fluxes of $\sum_{16} \mathrm{PAHs}, \sum_{7}$ OCPs and $\sum_{21}$ PCBs were $1328.8 \pm 961.1 \mu \mathrm{g} \mathrm{m}^{-2} \mathrm{y}^{-1}, 5421.4 \pm 3426.7 \mathrm{ng} \mathrm{m}^{-2} \mathrm{y}^{-1}$ and $811.8 \pm 578.3 \mathrm{ng} \mathrm{m}^{-2} \mathrm{y}^{-1}$, respectively. The dry particulate deposition fluxes of $\sum_{7}$ OCPs and $\sum_{21}$ PCBs were much lower than that of $\sum_{16}$-PAHs, most likely due to the local heavy PAH emissions into the atmosphere. In addition, the wet deposition fluxes of $\sum_{16}$ PAHs and $\sum_{7}$ OCPs were $6667.1 \pm 1745.2$ and $87.5 \pm 72.1 \mu \mathrm{g} \mathrm{m}^{-2} \mathrm{y}^{-1}$, respectively, which were much more dominant over their dry particulate deposition fluxes. However, it has to be noted that only particles were considered for dry deposition, but both particulate and dissolved phases were included for wet deposition in this study.

The profile of particulate $\sum_{16}$-PAHs fluxes was dominated by B(ghi)P (12.8\%), Ind (11.4\%), Pyr (10.7\%), Phe (10.0\%) and Chry $(9.3 \%)$ on an annual basis; and in wet precipitation, the dominant pollutants were Naph, Phe, Flt and Pyr, accounting for $12.8 \%, 8.3 \%, 2.5 \%$ and $2.4 \%$ of the $\sum_{16}$-PAHs fluxes, respectively. Previous studies indicated that volatile organic compounds could be redistributed onto larger particles via gas-particle partitioning, while the less volatile compounds tend to stay on the particles on which they were emit- ted (Sahu et al., 2004; He and Balasubramanian, 2009b). One can see in Table 2 that the dry deposition fluxes of high molecular weight (HMW) PAHs are comparable to those of low molecular weight (LMW) PAHs. HMW PAHs have been reported to contribute more to the dry deposition (Gigliotti et al., 2002), this anomaly in present study may be because the particulate fractions of LMW PAHs in aerosols which prefer to be in coarse-mode readily settled. Table 2 clearly shows that the contribution of the LMW PAH pollutants in wet deposition was increased as compared to those in dry deposition. The main processes contributing to wet deposition fluxes of SVOCs are precipitation scavenging of particlesorbed and gaseous chemicals, but particle scavenging, rather than the gas scavenging, is the dominant removal mechanism (Offenberg and Baker, 2002; Sahu et al., 2004). The belowcloud scavenging rates increase with particle size because the collision efficiency of particle-droplet encounter increases with increasing particle diameters (Calderón et al., 2008). In this study, it is understandable that the washout of those volatile pollutants attached with coarse particles dominated the wet depositional flux of SVOCs such as LMW PAHs and $\mathrm{HCHs}$, considering the high rainfall amount and precipitation intensities in Singapore. However, scavenging of fine particles needs to be considered and could contribute as well via nucleation, Brownian diffusion and electrical charge effects (Perry and Hobbs, 1994; Chate, 2005). 
Table 2. Annual Mean Atmospheric Fluxes (Mean \pm S.D.) of selected SVOCs.

\begin{tabular}{|c|c|c|c|c|c|c|}
\hline Compound & Dry deposition & Wet deposition & Air-sea exchange $^{1}$ & Air-sea exchange $^{2}$ & Compounds & Dry Deposition \\
\hline PAHs & $\mu \mathrm{g} \mathrm{m}^{-2} \mathrm{y}^{-1}$ & $\mu \mathrm{g} \mathrm{m}^{-2} \mathrm{y}^{-1}$ & \multicolumn{2}{|c|}{$\mathrm{ng} \mathrm{m}^{-2}$ day $^{-1}$} & $\mathrm{PCBs}^{3}$ & $n g m^{-2} y^{-1}$ \\
\hline Naph & $65.3 \pm 56.0$ & $850.7 \pm 428.8$ & $-1608.4 \pm 869.6$ & $-902.4 \pm 487.9$ & CB $17+18$ & $58.8 \pm 34.5$ \\
\hline Acy & $28.0 \pm 13.1$ & $62.9 \pm 60.9$ & - & - & CB $28+31$ & $14.9 \pm 10.9$ \\
\hline Ace & $32.7 \pm 20.5$ & $102.7 \pm 106.5$ & $-36.5 \pm 8.0$ & $-17.8 \pm 3.9$ & CB 33 & $9.3 \pm 2.8$ \\
\hline Flu & $19.6 \pm 10.3$ & $82.6 \pm 46.0$ & $-27.3 \pm 22.0$ & $-13.3 \pm 10.7$ & CB $52+49$ & $34.5 \pm 22.4$ \\
\hline Phe & $130.6 \pm 78.4$ & $554.4 \pm 395.6$ & $-457.7 \pm 209.2$ & $-224.8 \pm 102.7$ & CB 44 & $31.7 \pm 22.4$ \\
\hline Ant & $19.6 \pm 14.0$ & $68.1 \pm 91.4$ & $-210.6 \pm 53.9$ & $-103.3 \pm 26.4$ & CB 74 & $29.9 \pm 23.3$ \\
\hline Flt & $112.0 \pm 88.6$ & $165.6 \pm 133.2$ & $-394.5 \pm 283.5$ & $-196.9 \pm 141.5$ & CB 70+95 & $17.7 \pm 13.1$ \\
\hline Pyr & $140.0 \pm 13.1$ & $162.2 \pm 156.5$ & $-674.4 \pm 359.3$ & $-337.4 \pm 179.8$ & CB 101 & $39.2 \pm 46.7$ \\
\hline $\mathrm{B}(\mathrm{a}) \mathrm{A}$ & $62.5 \pm 52.3$ & $47.2 \pm 39.2$ & $-192.2 \pm 137.4$ & $-96.8 \pm 69.2$ & CB 99 & $24.3 \pm 16.8$ \\
\hline Chry & $121.3 \pm 102.6$ & $108.3 \pm 95.2$ & $-825.1 \pm 669.0$ & $-430.3 \pm 348.9$ & CB 110 & $34.5 \pm 28.0$ \\
\hline $\mathrm{B}(\mathrm{b}) \mathrm{F}$ & $102.6 \pm 78.4$ & $142.1 \pm 107.7$ & $-383.1 \pm 131.7$ & $-259.7 \pm 89.3$ & CB 149 & $168.0 \pm 105.3$ \\
\hline $\mathrm{B}(\mathrm{k}) \mathrm{F}$ & $62.5 \pm 72.8$ & $12.4 \pm 14.3$ & $-405.6 \pm 386.8$ & $-274.5 \pm 261.7$ & CB $138+158$ & $121.3 \pm 79.3$ \\
\hline $\mathrm{B}(\mathrm{a}) \mathrm{P}$ & $75.6 \pm 89.6$ & $7.7 \pm 6.8$ & $-630.0 \pm 563.0$ & $-452.3 \pm 204.3$ & CB 171 & $63.5 \pm 9.3$ \\
\hline Ind & $149.3 \pm 168.0$ & $11.9 \pm 7.8$ & $-21.7 \pm 20.2$ & $-17.2 \pm 15.8$ & CB 177 & $43.9 \pm 21.5$ \\
\hline $\mathrm{DB}(\mathrm{ah}) \mathrm{A}$ & $39.2 \pm 67.2$ & $27.1 \pm 15.9$ & - & - & CB 180 & $51.3 \pm 49.5$ \\
\hline $\mathrm{B}(\mathrm{ghi}) \mathrm{P}$ & $168.0 \pm 121.3$ & $42.2 \pm 39.4$ & $-17.0 \pm 6.6$ & $-13.2 \pm 5.1$ & CB 183 & $72.8 \pm 9.3$ \\
\hline$\Sigma$ PAHs & $1328.8 \pm 961.1$ & $6,667.1 \pm 1,745.2$ & $-5884.0 \pm 2167.6$ & $-3340.1 \pm 1431.7$ & $\Sigma \mathrm{PCBs}$ & $811.8 \pm 578.3$ \\
\hline OCPs & $\mathrm{ng} \mathrm{m}^{-2} \mathrm{y}^{-1}$ & $\mu \mathrm{g} \mathrm{m}^{-2} \mathrm{y}^{-1}$ & \multicolumn{2}{|c|}{$\mathrm{ng} \mathrm{m}^{-2}$ day $^{-1}$} & & \\
\hline$\alpha-\mathrm{HCH}$ & $1847.6 \pm 1136.8$ & $45.5 \pm 36.8$ & $-73.7 \pm 31.3$ & $-40.9 \pm 17.4$ & & \\
\hline$\beta-\mathrm{HCH}$ & $625.2 \pm 439.8$ & $8.7 \pm 8.8$ & $-44.4 \pm 37.8$ & $-34.1 \pm 27.3$ & & \\
\hline$\gamma-\mathrm{HCH}$ & $1390.3 \pm 711.5$ & $24.4 \pm 19.1$ & $-48.4 \pm 30.4$ & $-27.2 \pm 17.1$ & & \\
\hline$\delta-\mathrm{HCH}$ & $933.1 \pm 765.2$ & $5.8 \pm 4.6$ & - & - & & \\
\hline 4,4'-DDD & $54.1 \pm 74.6$ & $0.45 \pm 0.44$ & $-2.9 \pm 1.8$ & $-1.5 \pm 0.90$ & & \\
\hline 4,4'-DDE & $41.1 \pm 35.5$ & $0.71 \pm 0.89$ & $-0.74 \pm 0.67$ & $-0.36 \pm 0.43$ & & \\
\hline 4,4'-DDT & $531.9 \pm 261.3$ & $1.9 \pm 1.4$ & $-1.1 \pm 0.85$ & $-0.58 \pm 0.43$ & & \\
\hline$\Sigma \mathrm{OCPs}$ & $5421.4 \pm 3426.7$ & $87.5 \pm 72.1$ & $-171.3 \pm 100.8$ & $-104.5 \pm 65.1$ & & \\
\hline
\end{tabular}

1 Air-sea exchange in Singapore's marine surface without surfactant coverage considered.

2 Air-sea exchange in Singapore's marine surface with surfactant coverage considered.

${ }^{3}$ Concentrations of PCBs in both dissolved and particulate phases of all rainwater and SSW and SML samples were below the limits of detection in this study.

\subsection{Water column partitioning}

In sea subsurface water (SSW), the apparent dissolved and particulate occurrence levels of SVOCs are reported in Table 3. The mean concentrations of PAHs were $43.9 \pm 35.8$ and $131.4 \pm 101.8 \mathrm{ng} \mathrm{L}^{-1}$ for both phases, respectively, showing a 3 -fold enrichment of PAHs in the suspended particulate-phase in this marine environment. For HCHs and DDXs, the total mean concentrations were $1147.8 \pm 898.5$ and $361.9 \pm 271.8 \mathrm{pg} \mathrm{L}^{-1}$ in the dissolved phase, and $728.9 \pm 622.0$ and $560.3 \pm 501.5 \mathrm{pg} \mathrm{L}^{-1}$ in the particulate phase, respectively. The levels of both HCHs and DDXs were comparable to those reported for Johor strait located between Singapore and Malaysia previously reported by Wurl et al. (2006b).

\subsubsection{Relationship between $K_{\mathrm{OC}}$ and $K_{\mathrm{OW}}$}

The organic carbon-normalized partition coefficients between particulate and dissolved phases $\left(K_{\mathrm{OC}}\right)$ for both PAHs and OCPs were obtained based on the data obtained from field measurements. The relationships between $K_{\mathrm{OC}}$ of PAHs and OCPs and their respective $K_{\mathrm{OW}}$ were investigated with the inclusion of predicted $K_{\mathrm{OC}}$ values by Karickhoff's model (Karickhoff, 1981) as in Fig. 2. In Fig. 2a, the observed $K_{\mathrm{OC}}$ values, especially for those PAHs with smaller $K_{\mathrm{OW}}$, are much larger than predictions and the $\log K_{\mathrm{OC}}$ is poorly correlated with $\log K_{\text {OW }}$ with low slope of 0.13 only. It has been suggested that the slope of the $\log K_{\mathrm{OC}} / \log K_{\mathrm{OW}}$ relation should be equal to 1 when partitioning is in equilibrium (Chiou et al., 1983; Gschwend and Wu, 1985). Researchers initially hypothesized that the significant deviation from 1 May mainly be due to the non-equilibrium or the 
Table 3. Concentrations of SVOCs in SSW, SML and atmospheric gas phases during November to December 2007 in Singapore's coastal area.

\begin{tabular}{|c|c|c|c|c|c|c|}
\hline \multirow[t]{2}{*}{ Compound } & \multicolumn{3}{|c|}{ SSW } & \multicolumn{2}{|c|}{ SML } & \multirow{2}{*}{$\begin{array}{l}\text { Gas } \\
C_{\mathrm{a}}{ }^{*}\end{array}$} \\
\hline & $C_{\mathrm{d}, \mathrm{a}^{*}}$ & $C_{\mathrm{P}}^{*}$ & $F_{\mathrm{DOC}, \mathrm{C}} *(\%)$ & $C_{\mathrm{d}, \mathrm{a}}{ }^{*}$ & $C_{\mathrm{P}}^{*}$ & \\
\hline PAHs & \multicolumn{2}{|c|}{$n g L^{-1}$} & & & & $\mathrm{ng} \mathrm{m}^{-3}$ \\
\hline Naph & $18.4 \pm 10.6$ & $33.5 \pm 23.8$ & $0.10 \pm 0.13$ & $19.6 \pm 16.1$ & $43.2 \pm 22.2$ & $8.7 \pm 6.0$ \\
\hline Ace & $0.58 \pm 0.39$ & $3.1 \pm 1.8$ & $0.32 \pm 0.47$ & $1.4 \pm 1.5$ & $2.7 \pm 1.6$ & $0.98 \pm 0.84$ \\
\hline Flu & $2.3 \pm 3.6$ & $6.1 \pm 4.6$ & $0.58 \pm 0.44$ & $4.7 \pm 3.5$ & $11.0 \pm 10.2$ & $3.7 \pm 3.2$ \\
\hline Phe & $6.2 \pm 2.0$ & $17.7 \pm 8.4$ & $1.4 \pm 1.2$ & $16.9 \pm 12.1$ & $60.6 \pm 20.5$ & $34.8 \pm 22.4$ \\
\hline Ant & $0.38 \pm 0.25$ & $1.5 \pm 2.6$ & $1.3 \pm 0.92$ & $2.1 \pm 3.0$ & $6.8 \pm 4.4$ & $3.4 \pm 1.8$ \\
\hline Flt & $5.8 \pm 9.1$ & $6.5 \pm 8.6$ & $5.5 \pm 3.2$ & $3.8 \pm 2.6$ & $17.2 \pm 3.3$ & $51.8 \pm 38.7$ \\
\hline Pyr & $1.1 \pm 0.43$ & $3.9 \pm 2.5$ & $5.1 \pm 5.7$ & $7.4 \pm 5.9$ & $19.6 \pm 4.5$ & $56.3 \pm 44.1$ \\
\hline $\mathrm{B}(\mathrm{a}) \mathrm{A}$ & $1.3 \pm 1.2$ & $9.2 \pm 5.9$ & $18.7 \pm 14.8$ & $2.5 \pm 2.1$ & $20.0 \pm 8.5$ & $15.1 \pm 25.9$ \\
\hline Chry & $1.5 \pm 1.4$ & $6.8 \pm 4.1$ & $17.3 \pm 12.0$ & $3.2 \pm 2.1$ & $26.5 \pm 14.7$ & $8.0 \pm 5.9$ \\
\hline $\mathrm{B}(\mathrm{b}) \mathrm{F}$ & $0.74 \pm 0.50$ & $5.6 \pm 5.2$ & $14.5 \pm 13.2$ & $4.2 \pm 2.2$ & $25.1 \pm 15.3$ & $1.9 \pm 0.96$ \\
\hline $\mathrm{B}(\mathrm{k}) \mathrm{F}$ & $0.58 \pm 0.36$ & $8.4 \pm 6.1$ & $21.4 \pm 19.1$ & $1.7 \pm 1.3$ & $27.9 \pm 18.5$ & $0.61 \pm 0.56$ \\
\hline $\mathrm{B}(\mathrm{a}) \mathrm{P}$ & $1.2 \pm 0.72$ & $15.7 \pm 11.0$ & $22.7 \pm 16.3$ & $4.5 \pm 4.2$ & $47.6 \pm 27.9$ & $0.85 \pm 0.74$ \\
\hline Ind & $0.91 \pm 1.6$ & $5.1 \pm 8.4$ & $42.5 \pm 23.9$ & $3.1 \pm 1.5$ & $12.7 \pm 8.7$ & $0.026 \pm 0.014$ \\
\hline DB(ah)A & $2.1 \pm 2.8$ & $0.97 \pm 0.72$ & $51.9 \pm 24.7$ & $1.9 \pm 1.3$ & $3.0 \pm 2.7$ & $0.010 \pm 0.007$ \\
\hline $\mathrm{B}(\mathrm{ghi}) \mathrm{P}$ & $0.87 \pm 0.79$ & $7.3 \pm 8.1$ & $40.7 \pm 23.8$ & $3.8 \pm 2.0$ & $26.3 \pm 12.5$ & $0.028 \pm 0.025$ \\
\hline$\sum$ PAHs & $43.9 \pm 35.8$ & $131.4 \pm 101.8$ & & $80.8 \pm 61.3$ & $365.3 \pm 209.1$ & $187.5 \pm 138.3$ \\
\hline OCPs & \multicolumn{2}{|c|}{$\operatorname{pg~L^{-1}}$} & & & & $\operatorname{pg~m}^{-3}$ \\
\hline$\alpha-\mathrm{HCH}$ & $403.3 \pm 206.7$ & $230.0 \pm 186.9$ & $0.26 \pm 0.37$ & $509.7 \pm 194.4$ & $465.5 \pm 249.9$ & $415.5 \pm 135.7$ \\
\hline$\beta-\mathrm{HCH}$ & $306.5 \pm 280.2$ & $326.6 \pm 258.9$ & $0.25 \pm 0.36$ & $835.3 \pm 533.9$ & $506.7 \pm 314.4$ & $238.6 \pm 143.1$ \\
\hline$\gamma-\mathrm{HCH}$ & $257.4 \pm 181.2$ & $112.7 \pm 131.4$ & $0.20 \pm 0.30$ & $232.2 \pm 240.2$ & $230.5 \pm 145.9$ & $195.9 \pm 193.6$ \\
\hline$\delta-\mathrm{HCH}$ & $180.6 \pm 230.4$ & $59.6 \pm 44.8$ & - & $310.5 \pm 319.5$ & $208.9 \pm 219.2$ & $109.1 \pm 101.3$ \\
\hline$\sum \mathrm{HCHs}$ & $1147.8 \pm 898.5$ & $728.9 \pm 622.0$ & & $1887.8 \pm 1288.1$ & $1411.7 \pm 929.5$ & $958.9 \pm 336.7$ \\
\hline 4,4'-DDD & $28.6 \pm 22.4$ & $8.7 \pm 7.9$ & $33.4 \pm 22.7$ & $39.3 \pm 36.9$ & $26.3 \pm 32.5$ & $7.5 \pm 5.9$ \\
\hline 4,4'-DDE & $91.2 \pm 50.5$ & $10.3 \pm 16.1$ & $40.1 \pm 33.9$ & $165.9 \pm 50.6$ & $34.6 \pm 20.3$ & $3.3 \pm 2.4$ \\
\hline 4,4'-DDT & $242.1 \pm 198.9$ & $541.3 \pm 477.5$ & $35.9 \pm 23.1$ & $290.6 \pm 130.2$ & $1179.8 \pm 872.4$ & $28.7 \pm 11.5$ \\
\hline$\sum \mathrm{DDXs}$ & $361.9 \pm 271.8$ & $560.3 \pm 501.5$ & & $493.4 \pm 214.1$ & $1240.7 \pm 925.1$ & $39.5 \pm 7.7$ \\
\hline
\end{tabular}

${ }^{*} C_{\mathrm{d}, \mathrm{a}}$ : concentration in apparent dissolved phase; $C_{\mathrm{P}}$, concentration in suspended particulate phase in seawater; $F_{\mathrm{DOC}, \mathrm{C}}$ : the fraction of SVOCs sorbed onto DOC; $C_{\mathrm{a}}$, concentration in atmospheric gas.

sorption of compounds to colloids but not particulate phase (Gschwend and $\mathrm{Wu}, 1985$ ). Till now, a number of studies have reported that the field measured $K_{\mathrm{OC}}$ values were higher than the theoretically predicted ones in many different settings such as lake, sediments, and rain water (Baker et al., 1991; Poster and Baker, 1996; Accardi-dey and Gschwend, 2002). These results suggest the presence of particulate phase like soot (black carbon), to which the parent PAHs are more strongly associated than with natural organic matter/carbon. In contrast, field-obtained $K_{\mathrm{OC}}$ values for OCPs are correlated better with $K_{\text {OW }}$ with a slope of 0.79 closer to theoretical value and greater $R^{2}=0.66$ (Fig. 2b). In addition, these $K_{\mathrm{OC}}$ for OCPs are typically lower, but agree better with the model simulations, indicating the dominant influence of organic-carbon on water column partitioning for OCPs. Similar observations for hydrophobic polychlorinated biphenyls (PCBs) have been widely reported as well (Baker et al., 1991; McGroddy et al., 1996; Poster and Baker, 1996).

\subsubsection{Sorption of PAHs to soot carbon}

The observed partition coefficients $\left(K_{\mathrm{P}}\right)$ between particulate and dissolved phases are compared with predicted values by Eq. (5) as shown in Fig. 3 for lower molecular weight (LMW) PAHs such as Flu, Phe, Ant, and Pyr and higher molecular weight (HMW) PAHs such as B(a)A, Chry, B(b)F, B(k)F, $\mathrm{B}(\mathrm{a}) \mathrm{P}$, and $\mathrm{B}$ (ghi)P. The use of Freundlich exponent $n=0.62$, which was derived for pyrene in sediment by Accardi-dey and Gschwend (2002), over-estimates the sorption of both LMW (Fig. 3a) and HMW (the predicted line not shown in Fig. 3b) to the particulates in Singapore's coastal sub-surface seawater using the measured $f_{\mathrm{OC}}$ and $f_{\mathrm{SC}}$ values, indicating the sorption dynamics may be different due to variations in specific surface areas and surface chemistries of soot carbons of various origins. Freundlich exponent $n$ was varied to achieve the best fit at $n=0.80$ for LMW PAHs and at $n=1.2$ for HMW compounds. Both optimized Freundlich exponents are not equal to one, implying that $K_{\mathrm{BC}}$ is dependent on 

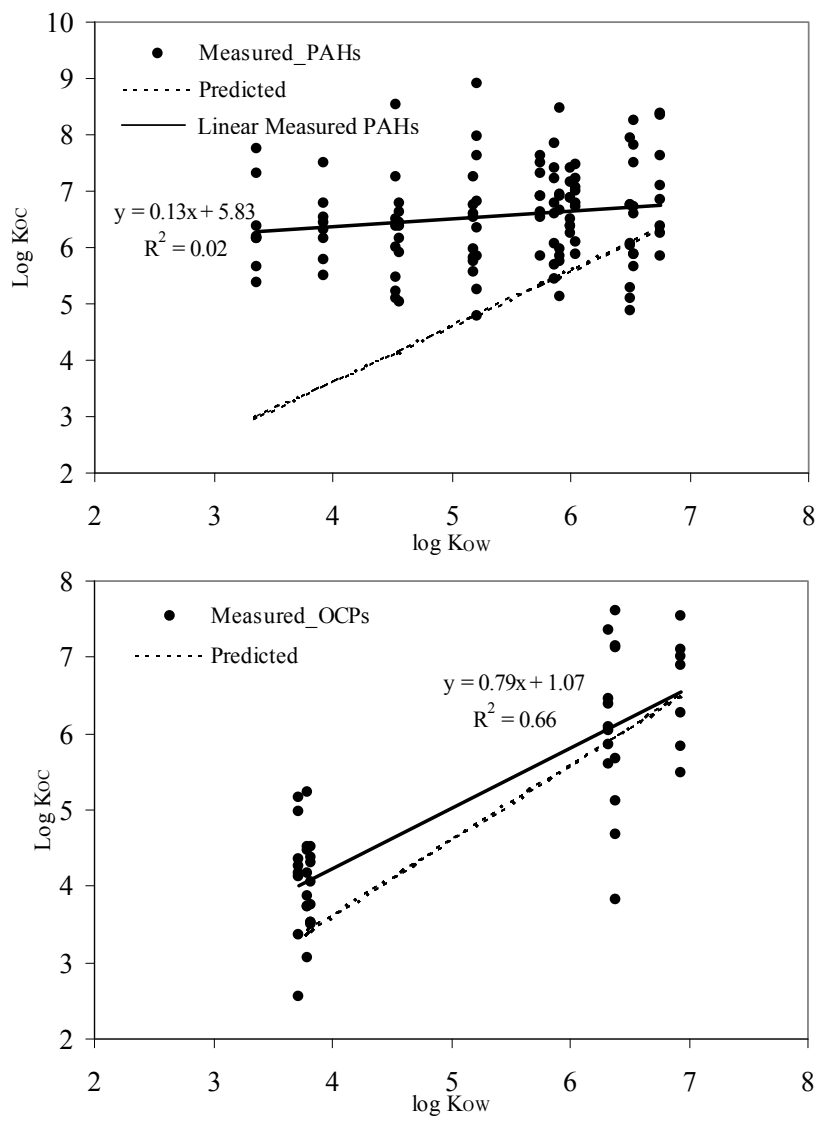

Fig. 2. Relationship between $\log K_{\mathrm{OC}}$ (measured and predicted) and $\log K_{\mathrm{OW}}$.

sorbate levels and the sorption of PAHs to soot carbon is a nonlinear process. For LMW PAHs such as Phe, Ant, Pyr, $n<1$ has been reported (Cornelissen and Gustafsson, 2005; Prevedouros et al., 2008), but for HMW compounds such as $\mathrm{B}(\mathrm{a}) \mathrm{P}, K_{\mathrm{P}}$ was over-predicted by a factor of $2-5$ by using $n<1$ (Prevedouros et al., 2008). At the optimum Freundlich exponents, $K_{\mathrm{P}}$ values increased by 1.4-1.6 log units and $0.7-$ $1.3 \log$ units for LMW and HMW PAHs, respectively. Soot carbon was the dominant sorbent here since its sorption contributed $\sim 90 \%$ of the total partition coefficients, while the OC fraction was still an important sorbent and contributed to $\sim 10 \%$ of the overall $K_{\mathrm{P}}$ values. It is hypothesized that sorptions onto both combustion-derived soot carbon and natural organic matter act in parallel to bind PAHs to particulate phase in marine water column. Additionally, it can be seen that the inclusion of soot carbon sorption reduced the dissolved water concentrations and increase the particulate enrichment of PAHs. The soot carbon fraction would lower the chemical availability of PAHs as compared to that expected from $f_{\mathrm{OC}} K_{\mathrm{OC}}$ alone so that the bioavailability may be reduced accordingly.
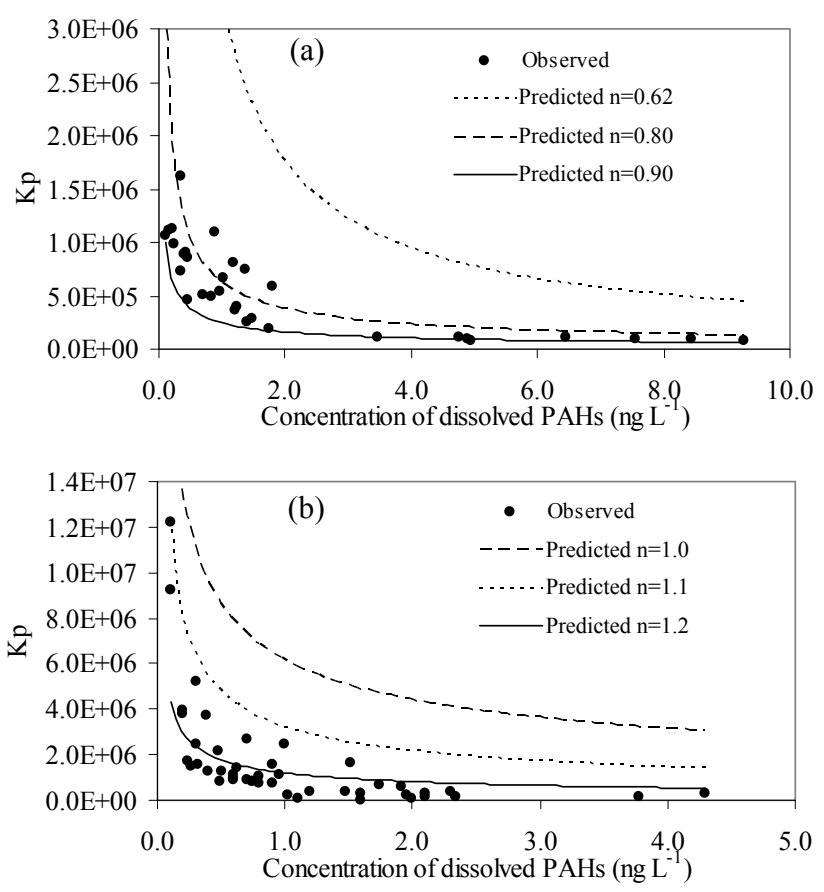

Fig. 3. Comparison of predicted and observed $K_{\mathrm{P}}$ (a) Flu, Phe, Ant, and Pyr, (b) B(a)A, Chry, B(b)F, B(k)F, B(a)P, and B(ghi)P.

\subsection{Air-water diffusive exchange}

\subsubsection{Truly dissolved SVOCs}

Those SVOCs sorbed onto colloidal matter (DOC) are not available for air-water exchange. The partitioning between truly dissolved and colloidal phases has to be investigated in order to obtain the truly dissolved concentrations of SVOCs. In this study, DOC concentrations are in the range of 0.6$7.8 \mathrm{mg} \mathrm{L}^{-1}$. The predicted mean fractions adsorbed to DOC for individual PAH varied in the range of $0.1-40 \%$ as can be seen from Table 3. It clearly showed that HMW PAHs are more readily adsorbed to DOC $(10-50 \%)$ than those LMW compounds (below 10\%). $\alpha-, \beta-$, and $\gamma-\mathrm{HCH}$ were adsorbed to DOC at a mean fraction of $0.26,0.25$ and $0.20 \%$, consistent with the values $(\sim 0.4 \%)$ reported by Wurl et al. (2006b), while $F_{\mathrm{DOC}, \mathrm{C}}(\%)$ for DDXs was much higher in the range of $30-40 \%$. This distribution pattern suggests that the sorption of SVOCs onto DOC in the seawater is correlated with the chemical's $K_{\mathrm{OW}}$, namely, pollutants with higher $K_{\mathrm{OW}}$ are more easily sorbed onto DOC.

\subsubsection{Air-water gas exchange flux for clean sea surface scenario}

Atmospheric gas-phase mean concentrations of $\sum$ PAHs, $\sum \mathrm{HCHs}$ and $\sum$ DDXs during November and December of 2007 (Table 3) were $187.5 \pm 138.3 \mathrm{ng} \mathrm{m}^{-3}$, $958.9 \pm 336.7 \mathrm{pg} \mathrm{m}^{-3}$ and $39.5 \pm 7.7 \mathrm{pg} \mathrm{m}^{-3}$, respectively, 
which were in the range of levels reported previously (He et al., 2009). The first scenario investigated here was for the Singapore's marine surface presumably without surfactant coverage. The mean annual fluxes of SVOCs across the air-water interface were estimated and are summarized in Table 2.

The fluxes of the individual PAH compound were in the range of $-21.7 \pm 20.2 \sim-1608.4 \pm 869.6 \mathrm{ng} \mathrm{m}^{-2}$ day $^{-1}$ and $\sum$ PAH flux reached up to $-5884.0 \pm 2167.6 \mathrm{ng} \mathrm{m}^{-2}$ day $^{-1}$. All PAHs showed negative fluxes indicating the tendency to transfer these contaminants from air to water (net absorption). The magnitude and direction of PAH fluxes varied widely on temporal and spatial scales all over the world. In Chesapeake Bay, individual fluxes ranged from $14.2 \mu \mathrm{g} \mathrm{m}^{-2} \mathrm{y}^{-1}$ net volatilization of Flu to $11.4 \mu \mathrm{g} \mathrm{m}^{-2}$ day $^{-1}$ net absorption of Phe on different sampling events (Bamford et al., 1999). Both New York harbor and Raritan Bay systems exhibited net volatilization fluxes for the majority of PAHs (Gigliotti et al., 2002), while LMW PAHs showed positive fluxes and HMW PAHs showed negative values in Mumbai harbor of India (Pandit et al., 2006). The magnitudes of net PAH fluxes are comparable to the reported values $\left(-0.01 \sim-21.2 \mu \mathrm{g} \mathrm{m}^{-2} \mathrm{day}^{-1}\right)$ in an urban lake in Guangzhou of China (Li et al., 2009). The large net absorption fluxes in this island were likely a result of high gaseous concentrations of PAHs, attributed to the highly uniform ambient temperature and the strong terrestrial sources such as island-wide vehicular traffic, chemical industries, major power plants and oil refineries.

Air-water gas exchange fluxes were estimated in the range of $-44.4 \pm 37.8 \sim-73.7 \pm 31.3 \mathrm{ng} \mathrm{m}^{-2} \mathrm{day}^{-1}$ and $-0.74 \pm 0.67 \sim-2.9 \pm 1.8 \mathrm{ng} \mathrm{m}^{-2} \mathrm{day}^{-1}$ for $\mathrm{HCHs}$ and DDXs, respectively (Table 2), indicating Singapore's south coastal line as a sink for both HCHs and DDXs. The fluxes estimated here were comparable to those for the Johor strait located between Singapore and Malaysia with $-8.2 \sim-66.8 \mathrm{ng} \mathrm{m}^{-2} \mathrm{day}^{-1}$ (Wurl et al., 2006a). It has been reported that air-water gas exchange of SVOCs is a dynamic process that is especially sensitive to fluctuations in concentrations of both air and water phases (Wilkinson et al., 2005). Even though the Henry's law constants of DDXs are larger than those of $\mathrm{HCHs}$, their net absorption was still much lower than that of $\mathrm{HCHs}$, most likely due to much higher occurrence levels of gaseous $\mathrm{HCHs}$, driving more $\mathrm{HCHs}$ transferred across the air-sea interface.

\subsubsection{Sea-surface microlayer enrichment}

SML has an enrichment effect of SVOCs, most likely due to their hydrophobic character and great affinity for surfactants collected at the air-water interface (Hardy, 1982; Chernyak et al., 1996; Wurl et al., 2006a). This effect can be quantified by the enrichment factor EF, calculated as the ratio between SML and SSW concentrations (Manodori et al., 2006) as shown in Fig. 4. EFs in the SML of particulate phase were
1.2-7.1 and 3.0-4.9 for PAHs and OCPs, and those of dissolved phase were 1.1-4.9 and 1.6-4.2 for PAHs and OCPs, respectively. EFs in the SML for $\mathrm{HCHs}$ found in this study were relatively higher than those reported for the Johor Strait between Malaysia and Singapore (EF=1.1-1.4 for particulate phase and $\mathrm{EF}=3.3-4.4$ for dissolved phase) by Wurl and Obbard (2006b). Similar profiles were found in the SML that EFs generally increased with an increase in molecular weight for both particulate and dissolved phases. In addition, the individual components exhibited similar trends in both phases, with relatively higher enrichments for particulate than for dissolved SVOCs. It is known that the major harbor, one of the busiest harbors in the world, is in the south coastal line of Singapore, and chemical industries as well as oil refineries situated in a group of small islands on the southwest coast of the Singapore Island. It is understandable that more organic film floats in the south coastal surface than in the north area (Johor Strait), resulting in more SVOCs enriched in the SML of the south coastal area. In addition, the SML is a relatively dynamic compartment, highly influenced by changes of the meteorological and hydrographical conditions (Guitart et al., 2007). This may be the reason for high variation of EFs obtained in this study.

\subsubsection{Air-water gas exchange flux for sea surface with microlayer coverage scenario}

As discussed above, high EFs indicated that SML in this marine area really has larger storage capacity (per volume) and may be able to delay the transport of SVOCs across the interface to SSW. Air-water gas exchange fluxes were also estimated for surfactant covered sea surface and presented in Table 2; the comparison was made between these two scenarios (Singapore's marine surface with and without surfactant coverage) in Fig. 5.

In the case of surfactant free Singapore's marine surface, the net fluxes of the individual PAH compound were in the range of $-13.3 \pm 10.7 \sim-902.4 \pm 487.9 \mathrm{ng} \mathrm{m}^{-2}$ day $^{-1}$ and $\sum$ PAH flux reached up to $-3340.1 \pm 1431.7 \mathrm{ng} \mathrm{m}^{-2}$ day $^{-1}$. In addition, the net fluxes were estimated in the range of $-27.2 \pm 17.1 \sim-40.9 \pm 17.4 \mathrm{ng} \mathrm{m}^{-2} \mathrm{day}^{-1}$ and $-0.36 \pm 0.43 \sim-1.5 \pm 0.9 \mathrm{ng} \mathrm{m}^{-2} \mathrm{day}^{-1}$ for $\mathrm{HCHs}$ and DDXs, respectively (Table 2). It can be seen that the surfactant covered marine surface reduced the net fluxes of all individual SVOCs studied here. Figure 5 shows that the reduction percentage of net fluxes by surfactants ranges from $21.0 \%$ (Ind) to $51.3 \%$ (Flu) for PAHs and from $23.1 \%$ $(\beta-\mathrm{HCH})$ to $51.1 \%$ (4, 4'-DDE) for OCPs, respectively. However, as Asher (1997) pointed out that Eq. (2) represents the maximum reduction of transfer velocity in terms of possible parameterizations of the effect of oceanic surfactants on $K_{\mathrm{w}, \mathrm{comp}}$, the surface coverage scenario represents the maximum effects of surfactants in the microlayer on a liquid-phase controlled transfer process. 


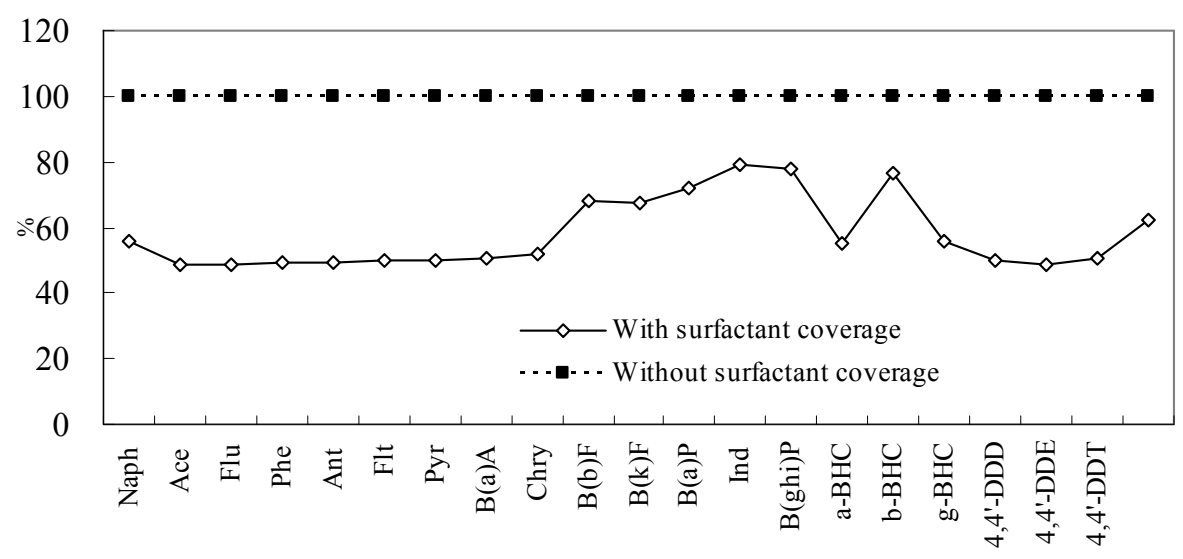

Fig. 4. The comparison of air-sea gas exchange fluxes of SVOCs for two different scenarios in Singapore's marine surface (with and without surfactant coverage).

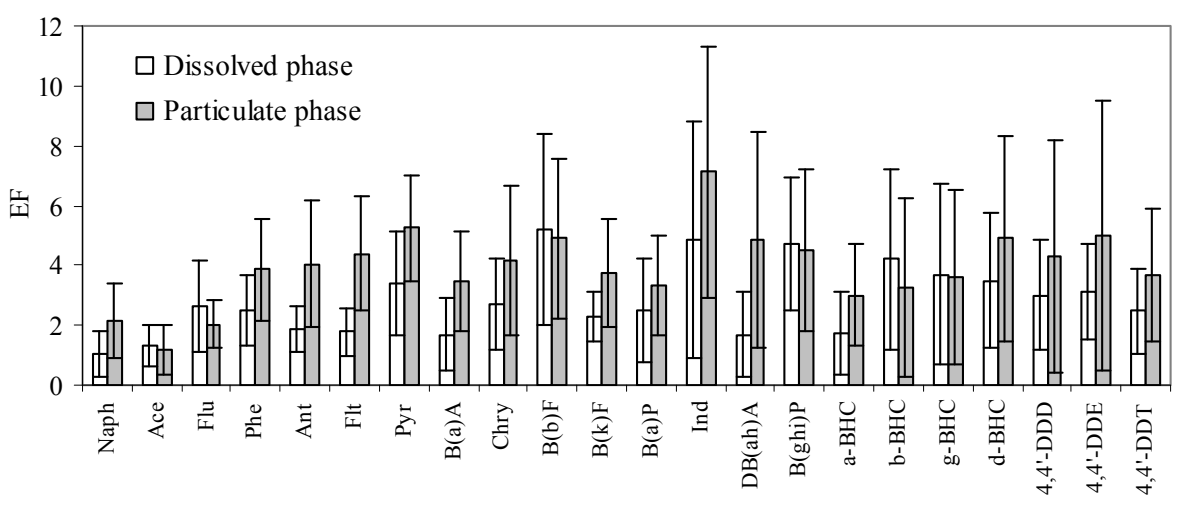

Fig. 5. Enrichment factors (EF) of PAHs and OCPs in the sea-surface microlayer of Singapore's coastal line.

By including the microlayer effect, perhaps the air-sea gas exchange fluxes of SVOCs on Singapore's marine surface could be more accurately estimated. Annual air-sea gas exchange fluxes for this scenario were calculated by multiplying the average daily fluxes by 365 days and the relative contribution of each depositional process to the total atmospheric deposition is shown in Fig. 6. For OCPs, most contribution to total OCP inputs was from wet deposition and air-sea exchange gas fluxes, while the dry particulate deposition dominated the total PAH inputs for Ind and $\mathrm{B}(\mathrm{ghi}) \mathrm{P}$ with $\sim 80 \%$ of contribution. As molecular weight increases from the low- to medium-molecular weight PAHs, dry deposition fluxes contribution generally increased, reflecting more fractions on particles. Wet deposition dominated the total PAH inputs for LMW compounds from Naph to Phe, and the profile of wet deposition contribution to total PAH inputs (Fig. 5) was similar to that of wet deposition fluxes for individual PAH compounds (Table 2). The contribution of air-sea gas absorption has been reported to decrease with the increasing of molecular weight (Gigliotti et al., 2002). However, in this study, it mostly prevailed for medium and high molecu- lar weight compounds from Ant to B(a)P, but not for LMW PAHs. This may be because the volatile degassing of these LMW compounds from the seawater to air under this tropical climate offsets their transfer from gas to seawater and led to the relatively low net absorption flux weightage observed here.

\subsubsection{Error analysis}

The concentration levels of SVOCs in the atmosphere and rainwater are critical to the flux estimations, and the uncertainty of these values could be minimized by using appropriate quality assurance protocols for the entire experimental procedures as mentioned above. For estimation of airsea gas diffusive exchange fluxes, parameters such as $K_{\mathrm{a}}$ and $K_{\mathrm{w}}$ (mass transfer coefficients across the air layer and water layer) were calculated by taking into account ambient atmospheric conditions while Henry's law constant was adopted from the literature. Error analysis has been applied onto this natural distribution process. In accordance with all the equations involved in this study, it can be seen that uncertainty in the estimated air-sea exchange fluxes was generally derived 


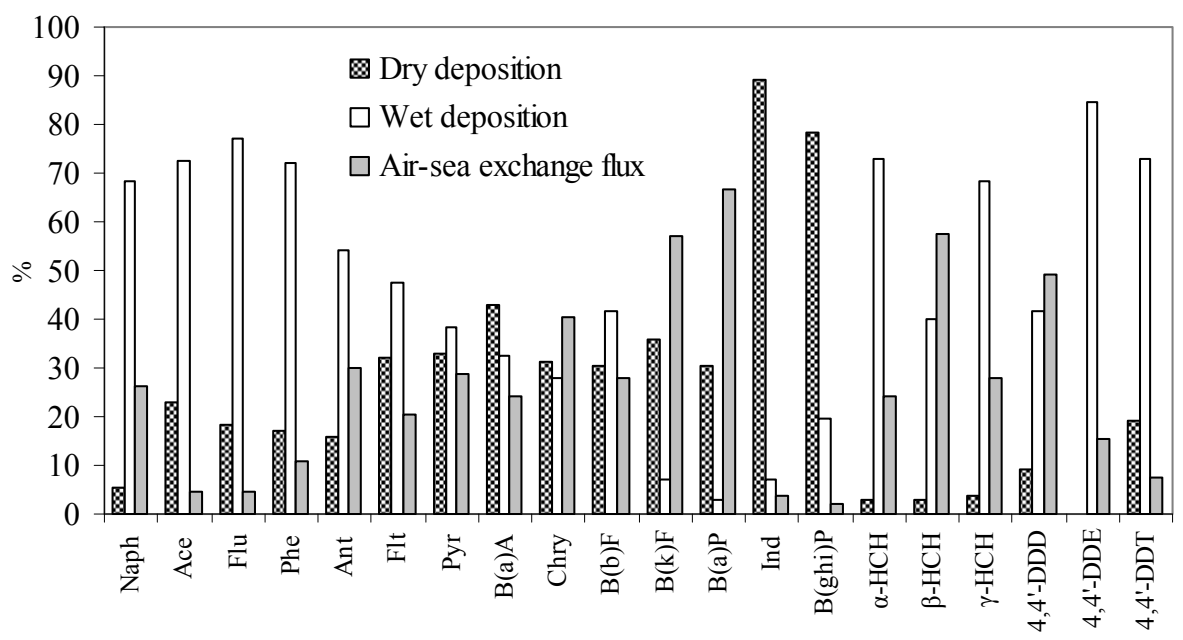

Fig. 6. The relative importance of dry particulate deposition, wet deposition, and air-sea gas exchange flux to total atmospheric deposition in the Singapore' south coastal area.

from systematic and random errors in the analysis. Systematic errors resulted from the values of $H$ and also from uncertainties in the estimation of the mass transfer coefficients. To assess the random errors in the air-sea exchange fluxes, a propagation of error analysis (Shoemaker et al., 1996) was performed by Eq. (12):

$$
\begin{aligned}
\sigma^{2}(F) & =\left(\frac{\delta F}{\delta K_{\mathrm{OL}}}\right)^{2}\left(\sigma K_{\mathrm{OL}}\right)^{2}+\left(\frac{\delta F}{\delta C_{\text {truly }}}\right)^{2}\left(\sigma C_{\text {truly }}\right)^{2} \\
& +\left(\frac{\delta F}{\delta C_{\mathrm{a}}}\right)^{2}\left(\sigma C_{\mathrm{a}}\right)^{2}+\left(\frac{\delta F}{\delta H}\right)^{2}(\sigma H)^{2}
\end{aligned}
$$

Total propagated variance $\left[\sigma^{2}(F)\right]$ is the linear combination of the weighted contribution of the variances $\left(\sigma^{2}\right)$ of the mass transfer coefficient, $H$, and measured concentrations. The term $(\sigma H)$ was assumed to be equal to zero because $H$ is a constant; and deviations originating from incorrect temperature and salinity corrections of $\mathrm{H}$ are taken as systematic errors. Uncertainties in the quantification of PAHs and OCPs in the water and air were estimated to be $8 \%$, as determined by the average standard deviation of the duplicate analysis of each samples with internal standard correction for calibration. Uncertainty in the mass transfer coefficients has been assumed to be $40 \%$ (Nelson et al., 1998), based on the errors in the air- and water-side transfer velocities $(K a$ and $K w)$. Using these estimated errors, the overall random error in the air-sea gas exchange fluxes was $\sim 36 \%$ (mean, ranging between 26\%-64\%). Overall, the error analysis showed that the major source of uncertainty in the estimation of the airsea exchange flux was the calculation of the mass transfer coefficient. It is believe that a better understanding of the mass transfer process will lead to an improved accuracy of flux estimations.

\section{Conclusions}

Both dry and wet depositions were estimated on the basis of the monthly concentrations of SVOCs. The dry particulate deposition showed lower fluxes during the monsoon seasons but a significant increase within the pre-NE monsoon. It was also observed that the high wet deposition fluxes took place during the rainy season (December 2007-March 2008) in sharp contrast to the low dry deposition fluxes during the same period. It has to be noted that the deposition profile was significantly influenced by meteorological/atmospheric conditions in this study. In SSW, the observed organic carbonnormalized partition coefficients between particulate and dissolved phases $\left(K_{\mathrm{OC}}\right)$ values for PAHs were much larger than predictions and the $\log K_{\mathrm{OC}}$ is poorly correlated with $\log$ $K_{\mathrm{OW}}$, while the field-obtained $K_{\mathrm{OC}}$ values for OCPs are correlated better with $K_{\mathrm{OW}}$. The study of sorption of PAHs to soot carbon showed that soot carbon was the dominant sorbent for PAHs since its sorption contributed $\sim 90 \%$ of the total partition coefficients, indicating soot carbon sorption reduced the dissolved water concentrations and possibly lowered the bio-availability of these pollutants in the sea water column. Other than the soot sorbent, colloidal matter (DOC) also played an important role in the partitioning of SVOCs in the water column, and reduced the availability of SVOCs for air-water exchange. In the air-water exchange study, all mean negative gas exchange fluxes showed net absorption of SVOCs onto the Singapore's south coastal sea-surface. In addition, the air-sea gas exchange fluxes were reduced by considering the sea surface microlayer coverage. The contribution of this process mostly prevailed for medium and high molecular weight compounds from Ant to B(a)P, but not for LMW PAHs as compared to dry particulate and wet depositions. Lastly, in the investigation of SML enrichment, a similar increasing trend of EFs for both particulate and dissolved 
phases was found with an increase in molecular weight and the individual components had relatively higher enrichments for particulate than for dissolved SVOCs. In addition, this study also implied that SML may have the large storage capacity to delay the transport of SVOCs across the interface to SSW.

Acknowledgements. The authors gratefully acknowledge the financial support of this research project by the financial support provided by the Singapore-Delft Water Alliance (R-264-001-013272).

Edited by: W. E. Asher

\section{References}

Accardi-dey, A. and Gschwend, P. M.: Assessing the combined roles of natural organic matter and black carbon as sorbents in sediments, Environ. Sci. Technol., 36, 21-29, 2002.

Achman, D. R., Hornbuckle, K. C., and Eisenreich, S. J.: Volatilization of polychlorinated biphenyls from Green Bay, Lake Michigan, Environ. Sci. Technol., 27, 75-87, 1993.

Asher, W. E.: The sea-surface microlayer and its effects on global air-sea gas transfer, in: The Sea Surface and global Change, edited by: Liss, P. S. and Duce, R. A., Cambridge Univ. Press, New York, 251-286, 1997.

Asher, W. E. and Pankow, J. F.: The interaction of mechanically generated turbulence and interfacial film with a liquid phase controlled gas/liquid transport process, Tellus, Ser. B, 38, 305-318, 1986.

Bahadur, N. P., Shiu, W. Y., Boocock, D. G. B., and Mackay, D.: Temperature dependence of octanol-water partition coefficient for selected chlorobenzenes, J. Chem. Eng. Data, 42, 685-688, 1997.

Baker, J. E., Eisenreich, S. J., and Eadie, B. J.: Sediment trap fluxes and benthic recycling of organic carbon, polycyclic aromatic hydrocarbons, and polychlorobiphenyl congeners in Lake Superior, Environ. Sci. Technol., 25, 500-509, 1991.

Bamford, H. A., Offenberg, J. H., Larsen, R. K., Ko, F. C., and Baker, J. E.: Diffusive exchange of polychclic aromatic hydrocarbons across the air-water interface of the Patapsco river, an urbanized subestuary of the Chesapeake Bay, Environ. Sci. Technol., 33, 2138-2144, 1999.

Basheer, C., Obbard, J. P., and Lee, H. K.: Persistent organic pollutants in Singapore's coastal marine environment: part I, seawater, Water Air Soil Pollut., 149, 295-313, 2003.

Bidleman, T. F., Jantunen, L. M., Falconer, R. L., Barrie, L. A., and Fellin, P.: Decline of hexachlorocyclohexane in the Arctic atmosphere and reversal of air-sea gas exchange, Geophys. Res. Lett., 22, 219-222, 1995.

Broecker, H.-C., Petermann, J., and Siems, W.: The influence of wind on $\mathrm{CO}_{2}$-exchange in a wind-wave tunnel, including the effects of monolayers, J. Mar. Res., 36, 595-610, 1978.

Calderón, S. M., Poor, N. D., Campbell, S. W., and Hartsell, B.: Rainfall scavenging coefficients for atmospheric nitric acid and nitrate in a subtropical coastal environment, Atmos. Environ., 42, 7757-7767, 2008.
Chate, D. M.: Study of scavenging of submicron-sized aerosol particles by thunderstorm rain events, Atmos. Environ., 39, 66086619, 2005.

Chen, S. F., Chan, R. C., Read, S. M., and Bromley, L. A.: Viscosity of sea water solutions, Desalination, 13, 37-51, 1973.

Chernyak, S. M., Rice, C. P., and McConnell, L. L.: Evidence of currently-used pesticides in air, ice, fog, seawater and surface microlayer in the Bering and Chukchi Seas, Mar. Pollut. Bull., 32, 410-419, 1996.

Chiou, C. T., Porter, P. E., and Schmedding, D. W.: Partition equilibria of non-ionic organic-compounds between soil organicmatter and water, Envrion. Sci. Technol., 17, 227-231, 1983.

Cornelissen, G. and Gustafsson, Ö.: Prediction of large variation in biota to sediment accumulation factors due to concentrationdependent black carbon adsorption of planar hydrophobic organic compounds, Environ. Toxicol. Chem., 24, 495-498, 2005.

Dachs, J., Lohmann, R., Ockenden, W. A., Mejanelle, L., Eisenreich, S. J., and Jones, K. C.: Oceanic biogeochemical controls on global dynamics of persistent organic pollutants, Environ. Sci. Technol., 36, 4229-4237, 2002.

Dachs, J. and Eisenreich, S. J.: Adsorption onto aerosol soot carbon dominates gas-particle partitioning of polycyclic aromatic hydrocarbons, Environ. Sci. Technol., 34, 3690-3697, 2000.

Dachs, J., Van Ry, D. A., and Eisenreich, S. J.: Occurrence of estrogenic nonylphenols in the urban and coastal atmosphere of the lower Hudson River estuary, Environ. Sci. Technol., 33, 26762679, 1999.

de Lima Ribeiro, F. A. and Ferreira, M. M. C.: QSPR models of boiling point, octanol-water partition coefficient and retention time index of polycyclic aromatic hydrocarbons, J. Mol. Struct., 663, 109-126, 2003.

Eisenreich, S. J., Looney, B. B., and Thornton, J. D.: Airborne organic contaminants in the Great Lakes ecosystem, Environ. Sci. Technol., 15, 30-38, 1981.

Fang, M., Ko, F., Baker, J. E., and Lee, C.: Seasonality of diffusive exchange of polychlorinated biphenyls and hexachlorobenzene across the air-sea interface of Kaohsung Harbor, Taiwan, Sci. Total Environ., 407, 548-565, 2008.

Frew, N. M., Goldman, J. C. Dennett, M. R. and Johnson, A.S .: Impact of phytoplankton-generated surfactants on air-sea gas exchange, J. Geophys. Res., 95, 3337-3352, 1990.

Gigliotti, C. L., Brunciak, P. A., Dachs, J., Glenn, T. R., and Nelson, E. D.: Air-water exchange of polycyclic aromatic hydrocarbons in the New York-New Jersey, USA, harbor estuary, Environ. Toxicol. Chem., 21, 235-244, 2002.

Gschwend, P. M. and Wu, S. C.: On the constancy of sediment water partition-coefficients of hydrophobic organic pollutants, Environ. Sci. Technol., 19, 90-96, 1985.

Guitart, C., García-Flor, N., Bayona, J. M., and Albaigés, J.: Occurrence and fate of polycyclic aromatic hydrocarbons in the coastal surface microlayer, Mar. Pollut. Bull., 54, 186-194, 2007.

Gustafsson, Ö., Haghseta, F., Chan, C. H., MacFarlane, J., and Gschwend, P. M.: Quantification of the dilute sedimentary soot phase: Implications for PAH speciation and bioavailability, Environ. Sci. Technol., 31, 3341-3347, 1997.

Hardy, J. T.: The sea surface microlayer: biology, chemistry and anthropogenic enrichment, Progr. Oceanogr., 11, 307-328, 1982.

Hart, K. M., Pankow, J. F.: High-volume air sampler for particle and gas sampling 2. Use of backup filters to correct for the adsorption 
of gas-phase polycyclic aromatic hydrocarbons to the front filter, Environ. Sci. Technol., 28, 655-661, 1994.

Harvey, G. W. and Burzell, L. A.: A simple microlayer method for small samples, Limnol. Oceanogr., 17, 156-157, 1972.

He, J. and Balasubramanian, R.: Determination of Atmospheric Polycyclic Aromatic Hydrocarbons Using Accelerated Solvent Extraction, Anal. Chem., 42, 1603-1619, 2009a.

He, J. and Balasubramanian, R.: A study of precipitation scavenging of semi-volatile organic compounds (SVOCs) in a tropical area, J. Geophys. Res., 114, D12201, doi:10.1029/2008JD011685, 2009b.

He, J. and Balasubramanian, R.: A study of gas/particle partitioning of SVOCs in the tropical atmosphere of Southeast Asia, Atmos. Environ., 43, 4375-4383, 2009c.

He, J., Balasubramanian, R., Karthikeyan, S., and Joshi, U. M.: Determination of semi-volatile organochlorine compounds in the atmosphere of Singapore using accelerated solvent extraction, Chemosphere, 75, 640-648, 2009.

Hinckley, D. A., Bidleman, T. F., and Rice, C. P.: Atmospheric organochlorine pollutants and air-sea exchange of hexachlorocyclohexane in the Bering and Chukchi Seas, J. Geophys. Res., 96, 7201-7213, 1991.

Hoff, R. M., Strachan, W. M. J., Sweet, C. W., Chan, C. H., Shackleton, M., Bidleman, T. F., Brice, K. A., Burniston, D. A., Cussion, S., Gatz, D. F., Harlin, K., and Schroeder, W. H.: Atmospheric deposition of toxic chemicals to the Great Lakes: a review of data through 1994, Atmos. Environ., 30, 3505-3527, 1996.

Iwata, H., Tanabe, S., Sakai, N., Nishimura, A., and Tatsukawa, R.: Geographical distribution of persistent organochlorines in air, water and sediments from Asia and Oceania, and their implications for global redistribution from lower latitudes, Environ. Pollut., 85, 15-33, 1994.

Iwata, H., Tanabe, S., Sakai, N., and Tatsukawa, R.: Distribution of persistent organochlorines in the oceanic air and surface seawater and the role of ocean on their global transport and fate, Envrion. Sci. Technol., 27, 1080-1098, 1993.

Jähne, B., Munnich, K. O., Bosinger, R., Dutzi, A., Huber, W., and Libner, P.: On the parameters influencing air-water gas exchange, J. Geophys. Res., 92, 1937-1949, 1987.

Jones, K. C. and De Voogt, P.: Persistent organic pollutants (POPs): state of science, Environ. Pollut., 100, 209-221, 1999.

Karickhoff, S. W.: Semi-empirical estimation of sorption of hydrophobic pollutants on natural sediments and soils, Chemosphere, 10, 833-846, 1981.

Kondo, Y., Morino, Y., and Takegawa, N., et al.: Impacts of biomass burning in Southeast Asia on ozone and reactive nitrogen over the western Pacific in spring, J. Geophys. Res., 109, D15S12, doi:10.1029/2003JD004203, 2004.

Lü, W., Chen, Y., Liu, M., Chen, X., and Hu, Z.: OSPR prediction of n-octanol/water partition coefficient for polychlorinated biphenyls, Chemosphere, 69, 469-478, 2007.

Lei, Y. D., Wania, F., Shiu, W. Y., and Boocock, D. G. B.: HPLCbased method for estimating the temperature dependence of $n$ octanol-water partition coefficient, J. Chem. Eng. Data, 45, 738742,2000

Li, J., Cheng, H., Zhang, G., Qi, S., and Li, X.: Polycyclic aromatic hydrocarbon (PAH) deposition to and exchange at the air-water interface of Luhu, an urban lake in Guangzhou, China, Environ. Pollut., 157, 273-279, 2009.
Liss, P. S. and Merlivat, L.: Air-sea gas exchange rates: introduction and synthesis, In The role of air-sea exchange in geochemical cycling, edited by: Buat-menard, P., Reidel, Hingham/Massachusetts, 113-127, 1986.

Luo, X., Mai, B., Yang, Q., Fu, J., Sheng, G., and Wang, Z.: Polycyclic aromatic hydrocarbons (PAHs) and organochlorine pesticides in water columns from the Pearl River and the Macao harbor in the Pearl River Delta in South China, Mar. Pollut. Bull., 48, 1102-1115, 2004.

Mackay, D., Shiu, W. Y., and Ma, K. C.:. Illustrated Handbook of Physical-Chemical Properties and Environmental Fate for Organic Chemicals, Lewis Publisher, Boca Raton, FL, 1992.

Mackay, D., Shiu, W. Y., and Ma, K. C.,: Illustrated Handbook of Physical-Chemical Properties and Environmental Fate for Organic Chemicals, Lewis Publishers, Boca Raton, FL, 1996.

Mader, B. T. and Pankow, J. F.: Gas/solid partitioning of semivolatile organic compounds (SOCs) to air filters. 3. An analysis of gas adsorption artifacts in measurements of atmospheric SVOCs when using Teflon membrane filters and quartz fiber filters, Environ. Sci. Technol., 35, 3422-3432, 2001.

Manodori, L., Gambaro, A., Piazza, R., Ferrari, S., Stortini, A. M., Moret, I., and Capodaglio, G.: PCBs and PAhs in sea-surface microlayer and sub-surface water samples of the Venice Lagoon (Italy), Mar. Pollut. Bull., 52, 184-192, 2006.

McGroddy, S. E., Farrington, J. W., and Gschwend, P. M.: Comparison of the in situ and desorption sediment-water partitioning of polycyclic aromatic hydrocarbons and polychlorinated biphenyls, Environ. Sci. Technol., 30, 172-177, 1996.

McVeety, B. D. and Hites, R. A.: Atmospheric deposition of polycyclic aromatic hydrocarbons to water surfaces: a mass balance approach, Atmos. Environ., 22, 511-536, 1988.

Nelson, E. D., McConell, L. L., and Baker, J. E.: Diffusive exchange of gaseous polycyclic aromatic hydrocarbons and polychlorinated biphenyls across the air-water interface of Chesapeake Bay, Environ. Sci. Technol., 32, 912-919, 1998.

Odabasi, M., Sofuoglu, A., Tasdemir, Y., and Holsen, T. M.: Measurment of dry deposition and air-water exchange of polycyclic aromatic hydrocarbons with the water surface sampler, Environ. Sci. Technol., 33, 426-434, 1999.

Offenberg, J. H., and Baker, J. E.: Precipitation scavenging of polychlorinated biphenyls and polycyclic aromatic hydrocarbons along an urban to over-water transect, Environ. Sci. Technol., 36, 3763-3771, 2002.

Oskam, I. C., Ropstad, E., Lie, E., Derocher, A. E., Wiig, Ø., Dahl, E., Larsen, S., and Skaare, J.U.: Organochlorines affect the steroid hormone cortisol in free-ranging polar bears (ursus Maritimus) at Svalbard, Norway, J. Toxicolo. Environ. Health, 67, 959-977, 2004.

Pandit, G. G., Sahu, S. K., Puranik, V. D., and Venkat Raj, V.: Exchange of polycyclic aromatic hydrocarbons across the air-water interface at the creek adjoining mumbai harbour, India, Environ. Int'l., 32, 259-264, 2006.

Park, J. S., Wade, T. L., and Sweet, S. T.: Atmospheric deposition of PAHs, PCBs and organochlorine pesticides to Corpus Christi Bay, Texas, Atmos. Environ., 36, 1707-1720, 2002.

Perry, K. D. and Hobbs, P. V.: Further evidence for particle nucleation in clear air adjacent to marine cumulus clouds, J. Geophys. Res., 99, 22803-22818, 1994.

Poster, D. L. and Baker, J. E.: Influence of submicron particles 
on hydrophobic organic contaminants and distributions of polycyclic aromatic hydrocarbons and polychlorinated biphenyls in rain water, Environ. Sci. Technol., 30, 341-348, 1996.

Prevedouros, K., Palm-Cousins, A., Gustafsson, Ö., and Cousins, I. T.: Development of a black carbon-inclusive multi-media model: Application for PAHs in Stockholm, Chemosphere, 70, 607-615, 2008.

Sahu, S. K., Pandit, G. G., and Sadasivan, S.: Precipitation scavenging of polycyclic aromatic hydrocarbons in Mumbai, India,, Sci. Total Environ., 318, 245-249, 2004.

Schwarzenbach, R. P., Geschwend, P. M., and Imboden, D. M. (eds.), Environmental organic chemistry, Wiley-Interscience, New York, 2003.

Seinfeld, J. H. and Pandis, S. N. (eds.): Atmospheric Chemistry and Physics: from Air Pollution to Climate Change (2nd ed), John Wiley, New York, 2006.

Shen, L. and Wania, F.: Compilation, evaluation, and selection of physical-chemical property data for organochlorine pesticides, J. Chem. Eng. Data, 50, 742-768, 2005.

Shoemaker, D. P., Garland, C. W., and Nibler, J. W.: Experiments in Physical Chemistry, McGraw-Hill, New York, 1996.

Totten, L. A., Brunciak, P. A., Gigliotti, C. L., Dachs, J., Glenn, T. R., Nelson, E. D., and Eisenreich, S. J.: Dynamic air-water exchange of polychlorinated biphenyls in the New York-New Jersey harbor estuary, Environ. Sci. Technol., 35, 3834-3840, 2001.

Tsai, W.-T. and Liu, K.-K.: An assessment of the effect of sea surface surfactant on global atmosphere-ocean $\mathrm{CO}_{2}$ flux, J. Geophys. Res., 108, 3127, doi:10.1029/2000JC000740, 2003.

Turner, D. B.: Comparison of Three Methods for Calculating the Standard Deviation of the Wind Direction, J. Climate Appl. Meteor., 25, 703-707, 1986.

van den Berg, A., Dentener, F., and Lelieveld, J.: Modelling the chemistry of the marine boundary layer: Sulfate formation and the role of sea-salt aerosol particles, J. Geophys. Res., 105, 11671-11698, 2000.

Wania, F.: Assessing the potential of persistent organic chemicals for long-range transport and accumulation in Polar regions, Environ. Sci. Technol., 37, 1344-1351, 2003.
Wania, F., Axelman, J., and Broman, D.: A review of processes involved in the exchange of persistent organic pollutants across the air-sea interface, Environ. Pollut., 102, 3-23, 1998.

Wanninkhof, R.: Relationship between wind speed and gas exchange over the ocean, J. Geophys. Res., 97, 7373-7382, 1992.

Wanninkhof, R., Sullivan, K. F., and Top, Z.: Air-sea gas transfer in the Southern Ocean, J. Geophys. Res., 109, C08S19.01C08S19.12, 2004.

Wilke, C. R. and Chang, P.: Correlation of diffusion coefficients in dilute solutions, AIChE J., 1, 264-270, 1955.

Wilkinson, A. C., Kimpe, L. E., and Blais, J. M.: Air-water gas exchange of chlorinated pesticides in four lakes spanning, Environ. Toxicol. Chem., 24, 61-69, 2005.

Wurl, O., Karuppiah, S., and Obbard, J. P.: The role of the seasurface microlayer in the air-sea gas exchange of organochlorine compounds, Sci. Total Environ., 369, 333-343, 2006 a.

Wurl, O. and Obbard, J. P.: Distribution of organochlorine compounds in the sea-surface microlayer, water column and sediment of Singapore's coastal environment, Chemosphere, 62, 1105$1115,2006 \mathrm{~b}$.

Wurl, O., Obbard, J. P., and Lam, P. K. S.: Distribution of organochlorines in the dissolved and suspended phase of the seasurface microlayer and seawater in Hong Kong, China, Mar. Pollut. Bull., 52, 768-777, 2006.

Xiao, H., Li, N., and Wania, F.: Compilation, evaluation, and selection of physical-chemical property data for $\alpha-, \beta$-, and $\gamma$ hexachlorocyclohexane, J. Chem. Eng. Data, 49, 173-185, 2004.

Zhang, G., Li, J., Cheng, H., Li, X., Xu, W., and Jones, K. C.: Distribution of organochlorine pesticides in the Northern South China Sea: Implications for land outflow and air-sea exchange, Environ. Sci. Technol., 41, 3884-3890, 2007.

Zhou, W. and Zhu, L.: Distribution of polycyclic aromatic hydrocarbons in soil-water system containing a nonionic surfactant, Chemosphere, 60, 1237-1245, 2005. 